\title{
Multi-Objective Function Approach of Optimizing Alkaline- Surfactant Polymer Flooding Performance using Particle Swamp Algorithm
}

\author{
Ejeh Chukwugozie Jekwu ${ }^{*}$, Idoniboye-Obu Boma ${ }^{2}$, Ebong Hanson ${ }^{3}$, Akhabue Gbemisola ${ }^{4}$ \\ Oil and Gas Engineering Department, School of Engineering \\ All Nations University College, Koforidua, Ghana
}

*Corresponding Author: Ejeh Chukwugozie Jekwu, Oil and Gas Engineering Department, School of Engineering

\begin{abstract}
The combination of alkaline, surfactant and polymer as a chemical enhanced oil recovery known as ASP flooding has been proved by both laboratory experiments and field applications to be the most promising chemical enhanced oil recovery method. Its promising nature is due to the various synergies that exist between the injected chemicals which reduce both interfacial tension and mobility ratio (that is ensuring stable displacement) to increase recovery. It is also known to be cost effective due to economic surfactant generated by the injection of alkaline and the reduction of adsorptions of both the artificial surfactant and polymer also caused by the presence of the alkaline thereby reducing the total amount of chemical injected. Nevertheless, ASP flooding is not without limitations. Its limitations include scale formation caused by the alkaline injected which gives various operational problems. Also, it has economic limitation mainly based on the cost of high volumes of chemicals injected. The technical and economic feasibility of implementation of ASP flooding therefore depends on the effective use of the chemicals injected and a slug formulation which mitigates scale formation. This study is on optimization of ASP flooding as a multi-objective problem using particle swarm optimization based on Pareto dominance. The objectives of this optimization process is to obtain a set of optimum ASP flooding designs (known as non-dominated set or Pareto set) that maximize recovery efficiency (FOE) and minimize total chemical utilized and the final $p H$ of the system. Analysis on the results of the optimization process revealed the optimum recovery efficiency $44.19 \%$ achievable by efficient use of the chemical injected and designs that mitigate scale formation by reducing the concentration of alkaline in the ASP slug formulation. Economic analysis on the Pareto set also confirmed the inference from the results of the optimization process and showed that with favourable oil price situation, recovering higher incremental oil by ASP flooding will be economically viable.
\end{abstract}

Index Terms: Alkaline Surfactant Polymer Flooding, Particle Swamp Optimization Enhanced Oil Recovery, Chemical Flooding and Alkaline Surfactant Polymer Flooding Optimization.

\section{INTRODUCTION}

Exploitation of petroleum resources can be put into three distinct phases: the primary, secondary and tertiary recovery (Figure 1). Averagely, only one third of the original oil in place (OOIP) is recovered by the conventional (primary and secondary) recovery methods worldwide (Kokal \& Al-Kaabi, 2010).

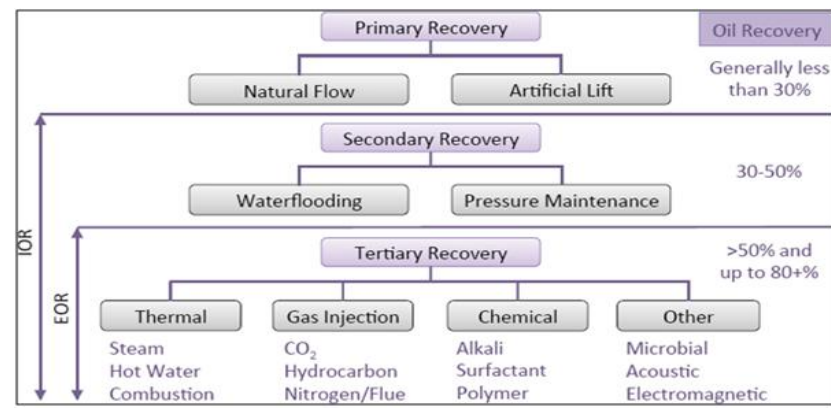

Figure1. Phase of oil recovery with recovery categories and associated recovery

Source: (National Research Council (US), 2013)

International Journal of Petroleum and Petrochemical Engineering (IJPPE) 
Currently, daily oil production is from mature or maturing oil fields and replacement of reserves is not catching up with the growing energy demand (Kokal \& Al-Kaabi, 2010). This is because discovery of new fields is progressively becoming difficult (Muggeridge, et al., 2014). The fluctuations in crude oil prices also result in high level of uncertainty and the collapse in exploration activities (Bashir, 2016; Gordon, 2015).

Maximizing the recovery factor of these mature and maturing fields has therefore been the focus of most oil companies lately to meet the growing energy demands. This has created conditions for the extensive deployment of enhanced oil recovery (tertiary) recovery methods (Muggeridge, et al., 2014). Enhanced oil recovery (EOR) involves attempts to recovery oil beyond that recovered by conventional methods. The target for EOR is to increase recovery to about two thirds of the original oil in place.

EOR techniques are basically grouped into three, based on the mechanisms for oil recovery. These mechanisms include reduction in oil viscosity, extraction of the oil with a solvent and the alteration of capillary and viscous forces between the oil, injected fluid and the rock surface (Kokal \& Al-Kaabi, 2010). Based on these mechanisms, the three main categories of EOR techniques include Thermal recovery, Miscible gas injection and Chemical methods.

Chemical flooding is one of the most practical enhanced oil recovery techniques for recovery residual oil in the reservoir left by water flooding (Sedaghat, et al., 2013). It involves the addition of chemicals to the water injected. The primary aim of chemical flooding is either to control mobility by the addition of polymer or reduce interfacial tension (IFT) by adding surfactant and/or alkaline. Early EOR techniques which involved using polymer alone were soon augmented by the addition of surfactant (Gogarty \& Tosch, 1968). Alkaline were added soon afterwards to reduce chemical adsorption by the rock and generate in-situ surfactant by reacting with acidic substance in the crude oil (Hill, et al., 1973).

\subsection{Asp Flooding Mechanisms}

The chemical flooding which involves the combination of polymer, surfactant and alkali injected as one solution slug is known as Alkaline-Surfactant-Polymer flooding (ASP flooding). Due to the synergetic actions of alkaline, surfactant and polymer, ASP flooding among other chemical flooding methods is the most promising (Sheng, 2013; Nedjhioui, et al., 2005). For better understanding of the mechanism involved in the ASP flooding process, it is vital to first review the various chemical components and the mechanisms involved in their various flooding processes.

\subsubsection{Alkaline Flooding Mechanisms}

The use of alkaline in chemical enhanced oil recovery (CEOR) involves the addition of the alkaline to the injected water. Alkaline is a basic, ionic salt of an alkali metal or alkaline earth metal. The common types of alkaline used in chemical flooding include sodium hydroxide $(\mathrm{NaOH}$, or caustic soda), sodium orthosilicate $\left(\mathrm{Na}_{4} \mathrm{SiO}_{4}\right)$ and sodium carbonate $\left(\mathrm{Na}_{2} \mathrm{CO}_{3}\right.$, or soda ash), sodium bicarbonate $\left(\mathrm{NaHCO}_{3}\right)$ and sodium metaborate $\left(\mathrm{NaBO}_{2}\right)$.

Alkaline flooding is a complex process which involves more than one mechanism in increasing oil recovery. The predominant mechanism is the reduction in IFT. The alkaline in the injected water reacts with organic acid (naphthenic acids) in crude oil to form in-situ surfactant (sodium naphthenate) in the reservoir. This economical surfactant aids in incremental oil recovery by lowering the IFT between oil and water. The reaction for the formation of the in-situ surfactant is represented by the chemical equation:

$\mathrm{HA}_{\mathrm{W}}+\mathrm{OH}^{-} \rightleftharpoons \mathrm{A}^{-}+\mathrm{H}_{2} \mathrm{O}$

Where $\mathrm{HA}_{\mathrm{W}}$ is the weak acid in the crude oil and $\mathrm{A}^{-}$is soap.

Increase in recovery is achieved in alkaline flooding by increasing alkaline concentration not alkaline type as shown in Figure 2 (Sedaghat, et al., 2013). Hongfu et al (2003) showed that increase in alkaline concentration results in a reduction in IFT to a minimum value of $10^{-4} \mathrm{mN} / \mathrm{m}$ at alkaline concentration of 0.8 wt. \% (Figure 3 ).

Other mechanisms involved in alkaline flooding include emulsification and alteration of rock wettability. These mechanisms can also become vital based on the rock and crude oil properties (Abadli, 2012).The mechanisms involved in alkaline flooding can be summarised as follows: 
Multi-Objective Function Approach of Optimizing Alkaline-Surfactant Polymer Flooding Performance using Particle Swamp Algorithm

- Emulsification and Entrainment: this involves process where the alkali moving through the reservoir entrains the crude oil.

- Wettability Alteration (from oil-wet to water-wet): changing the rock wettability from oil-wet to water-wet results in increase in relative permeability of oil.

- Wettability Alteration (from water-wet to oil-wet): this wettability alteration results in low residual oil saturation through lowering of interfacial tension.

- Emulsification and Entrapment: the movement of emulsified oil results in improved sweep efficiency

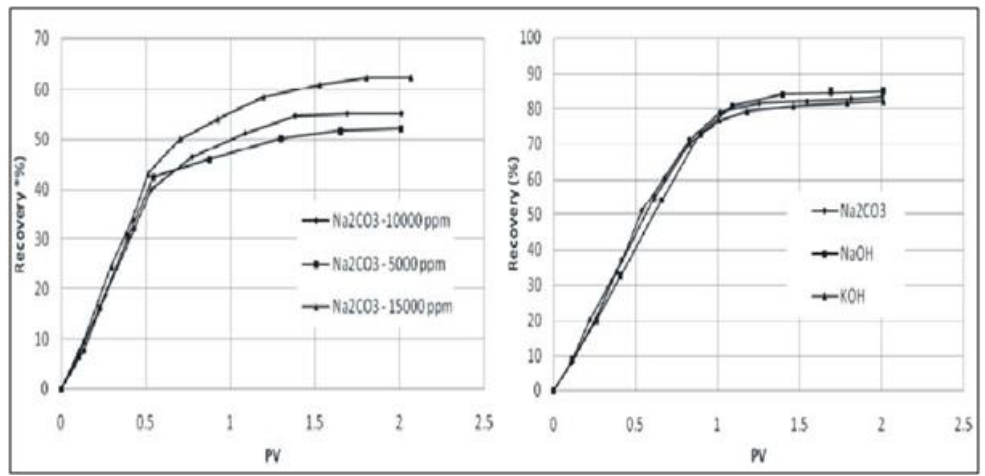

Figure2. Effect of alkaline concentration and type on oil recover

Source: (Sedaghat, et al., 2013)

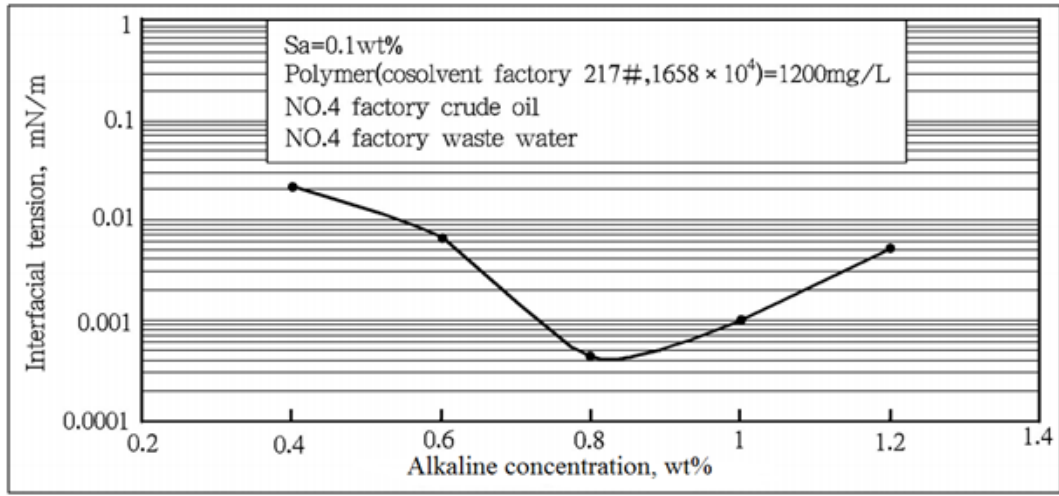

Figure3. Effect of alkaline concentration on IFT

Source: (Hongfu, et al., 2003)

Implementation of alkaline flooding is favourable in reservoirs with crude oil in the API range of $13^{\circ}$ to $35^{\circ}$ and specifically for oils with high organic acid content. Sandstones are preferred to carbonates when it comes to alkaline flooding due to the presences of anhydrite or gypsum which can consume large amount of alkaline chemical (Olaijire, 2014). Alkaline makes ASP economical by lowering surfactant and polymer adsorption thereby reducing the amount of chemical injected.

\subsubsection{Surfactant Flooding Mechanisms}

In the chemical flooding involving the use of surfactant (Surface Active Agent) as an agent for enhancing the recovery of oil, lowering of IFT is the main mechanism. The main purpose of surfactant flooding is to recover oil trapped by capillary forces after water flooding. Reduction in IFT can gets this oil moveable. For better understanding on the lowering of IFT as the mechanism for releasing capillary trapped residual oil, we consider the capillary number theory proposed by Foster and Lake (Youyi, et al., 2013).

Capillary number is defined as the ratio of displacement force to the capillary resistance force. This can be expressed as:

$\mathrm{N}_{\mathrm{c}}=\frac{\mu_{\mathrm{w}} \mathrm{v}}{\sigma_{\mathrm{ow}}} \#$

Where, $\mathrm{N}_{\mathrm{c}}$ is the capillary number, $\mu_{\mathrm{w}}$ is the viscosity of the displacing fluid, $\mathrm{v}$ is the velocity of the 
displacing fluid and $\sigma_{\mathrm{ow}}$ is the interfacial tension between oil and the displacing fluid. Experimental data show that as the capillary number increases, the residual oil saturation decreases (Stegemeier, 1997) as shown in Figure 4. Capillary number is usually around a value of $10^{-6}$ after water flooding. For a substantial increase in oil recovery, the capillary number must be decreased to a value around $10^{-3}$.

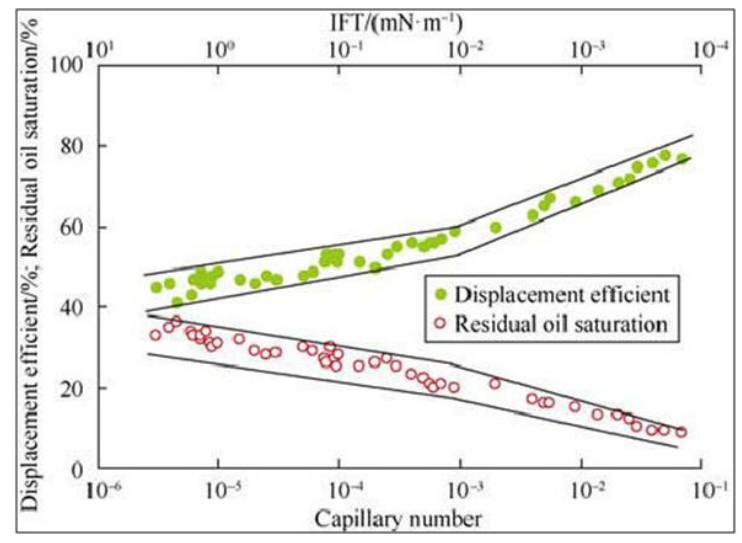

Figure4. Relationship between capillary number and residual oil saturation

Source: (Youyi, et al., 2013)

According to the capillary theory represented by the equation above, three ways are apparent in increasing capillary number. This includes increasing displacing fluid velocity, increasing displacing fluid viscosity and reduction in IFT between oil and the displacing fluid. Increasing displacing fluid velocity is limited by pump capacity and fracture pressure of the reservoir. Increasing viscosity of displacing fluid involves addition of polymer to the displacing fluid. This is costly due to the high cost of polymer. This implies that for surfactant as a chemical on its own for the purpose of chemical flooding will only involve IFT reduction as a means of increasing recovery.

Surfactant types normal used as agents for enhanced oil recovery include; PS (petroleum sulphonate), AOS ( $\alpha$-olefin sulphonate) and IOS (internal olefin sulphonate), AAS (alkyl-aryl sulphonate) and EA (ethoxylated alcohol) (Barnes, et al., 2010). Surfactant, in the presence of soap formed by the addition of alkaline, can decrease IFT to a value as low as $1 \times 10-4-5 \times 10-3 \mathrm{mN} / \mathrm{m}$. That is an increase of capillary number by 3 to 5 folds which will result in residual oil becoming mobile and increasing recovery.

\subsubsection{Polymer Floodiing Mechanisms}

Another area of chemical flooding of great importance is polymer flooding. Addition of polymer to injected water is to obtain a viscous displacing fluid thereby having a reduced mobility ratio to improve sweep efficiency. Two sets of polymers are widely used in EOR and this include synthetic polymers and biopolymers (Sorbie, 1991). Synthetic and partially hydrolysed polyacrylamide, modified natural polymers, biological polysaccharides and Xanthan are the most used polymers for EOR (Olaijire, 2014).

Mobility control is therefore a major mechanism in enhanced oil recovery process involving polymer injection. Mobility ratio is the ratio of the mobility of displacing fluid to that of the displaced fluid; In water flooding, it's the ratio of the mobility of water to that of oil

$\mathrm{M}=\frac{\lambda_{\mathrm{w}}}{\lambda_{\mathrm{o}}}=\frac{\frac{\mathrm{k}_{\mathrm{rw}}}{\mu} \mathrm{w}}{\frac{\mathrm{k}_{\mathrm{ro}}}{\mu_{\mathrm{o}}}}=\frac{\mathrm{k}_{\mathrm{rw}} \mu_{\mathrm{o}}}{\mathrm{k}_{\mathrm{ro}} \mu_{\mathrm{w}}} \#$

Where, $\mathrm{M}$ is mobility ratio, $\lambda_{\mathrm{o}}$ and $\lambda_{\mathrm{w}}$ are oil and water mobility respectively, $\mathrm{k}_{\mathrm{ro}}$ and $\mathrm{k}_{\mathrm{rw}}$ are the relative permeability of oil and water respectively and $\mu_{\mathrm{o}}$ and $\mu_{\mathrm{w}}$ are the viscosity of oil and water respectively

The concept of fractional flow gives better understanding of the effect of polymer on sweep efficiency when added to injected water. Fractional flow of oil can be defined as the ratio of oil flow rate to the total flow rate of oil and water. This can be illustrated mathematically as 
$f_{o}=\frac{q_{o}}{q_{w}+q_{o}} \#$

Where $f_{o}$ is fractional flow of oil, $q_{w}$ and $q_{o}$ is flow rate of water and oil respectively. With further assumptions, substitutions and simplification, the equation above can be expressed as

$f_{o}=\frac{1}{1+\frac{k_{r w} \mu_{o}}{k_{r o} \mu_{w}}}=\frac{1}{1+M} \#$

From equation 3, the fractional flow of oil and water sum up to one which means that the decrease in the flow of one fluid will eventual result in an increase in the flow of the other. It is apparent from equation 4 that, in order to increase the flow of oil (fo), mobility ratio must be decreased. Addition of polymer to displacing fluid increases the viscosity of the displacing fluid and also reduces its relative permeability. This reduces the mobility ratio, which leads to a stable displacement process with an increase in the flow of oil resulting in an improved recovery.

Polymer therefore does not only enhance the recovery of oil but also mitigate the production of water which improves the overall economics. Water production is mitigated due to the fact that viscous fingering is reduced by polymer (Figure 5) and the resulting improved sweep efficiency leads to injection of less water.

Viscoelasticity is also a vital property of polymer which aids in increasing oil displacement efficiency during polymer flooding. While the ultra-low IFT achieved by alkaline and surfactant is efficient in enhancing recovery in homogeneous reservoir, viscoelasticity contributes more in enhancing oil recovery in heterogeneous reservoir (Hou, et al., 2005). The viscoelasticity of polymer enhances the normal stress between oil and polymer solution. Polymer therefore exerts a large pulling force on oil droplets and causes the release of oil out of dead-end pore increasing recovery.

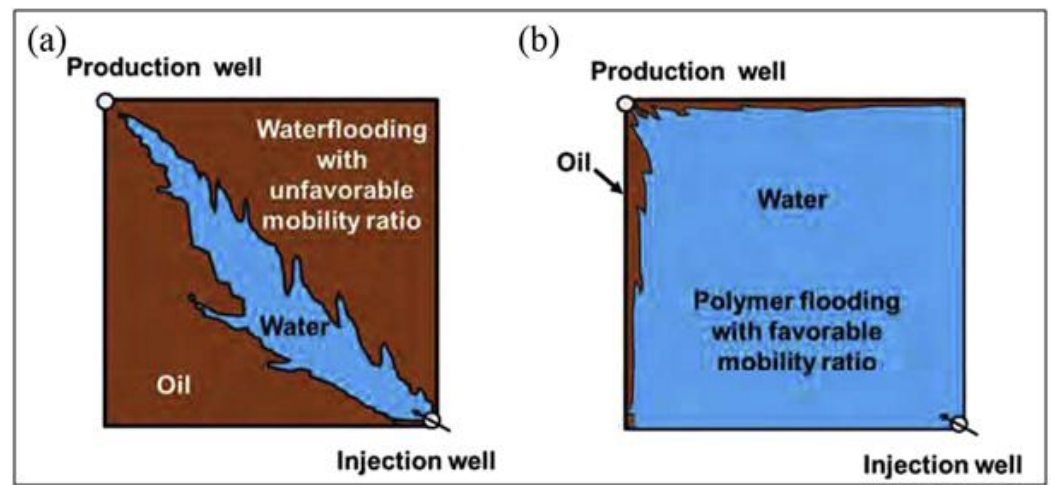

Figure5. (a) viscous fingering in water flooding (b) stable displacement in polymer augmented water flooding

Source: (Sydansk \& Romero-Zeron, 2011)

\subsubsection{Synergy In Asp Floodiing}

It has been proven by laboratory experiments (Olsen, et al., 1990) and field applications (Clark, et al., 1993; Shutang \& Qiang, 2010) that ASP flooding gives the highest recovery compared to other chemical flooding techniques. This is mainly due to the synergy created by the combination of these three chemicals. Pilot test and industrial field test on ASP flooding done in Daqing oil field have resulted in an incremental oil recovery of about $18.5 \%$ to $26.5 \%$. (Hongfu, et al., 2003).

Olson et al (1990) reported from laboratory study that the recovery achieved by ASP flooding is greater than the sum of the recoveries achieved by the chemical flooding involving the individual chemical component in ASP alone. This clearly shows the effectiveness of the synergism of ASP flooding.

The ASP flooding process involves injection of ASP main slug first which is followed by injection of polymer and then water. This sum up to about $60 \% \mathrm{PV}$ of the injected fluid. A typical ASP flooding injection sequence is shown in Figure 6. The polymer injected after the injection of the main ASP slug is to prevent viscous fingering of water into the ASP main slug. The injected water serves as a drive fluid that moves the injected fluids together with the oil bank towards the producers. 
There are various forms of synergies that take place by the combination of these three chemicals. Summarized below is a list of some of these synergies that makes ASP flooding more effective as compared to the individual chemicals (Sheng, 2013):

- The presence of alkaline reduces the adsorption of both surfactant and polymer

- Competition of adsorption between surfactant and polymer results in the reduction of adsorption of each chemical

- There is improved sweep efficiency of both alkaline and surfactant by the addition of polymer

- Soap (natural surfactant) is formed in-situ when injected alkaline react with the acidic content of the crude oil. Soap has very low optimum salinity whereas the injected surfactant has high optimum salinity. This result in a mixture of soap and surfactant with a wide range of salinity in which there is ultralow IFT

- Low IFT enhances the formation of emulsion which also improves microscopic and macroscopic sweep efficiency. Therefore, emulsion is made stable by soap and surfactant due to the ultralow IFT

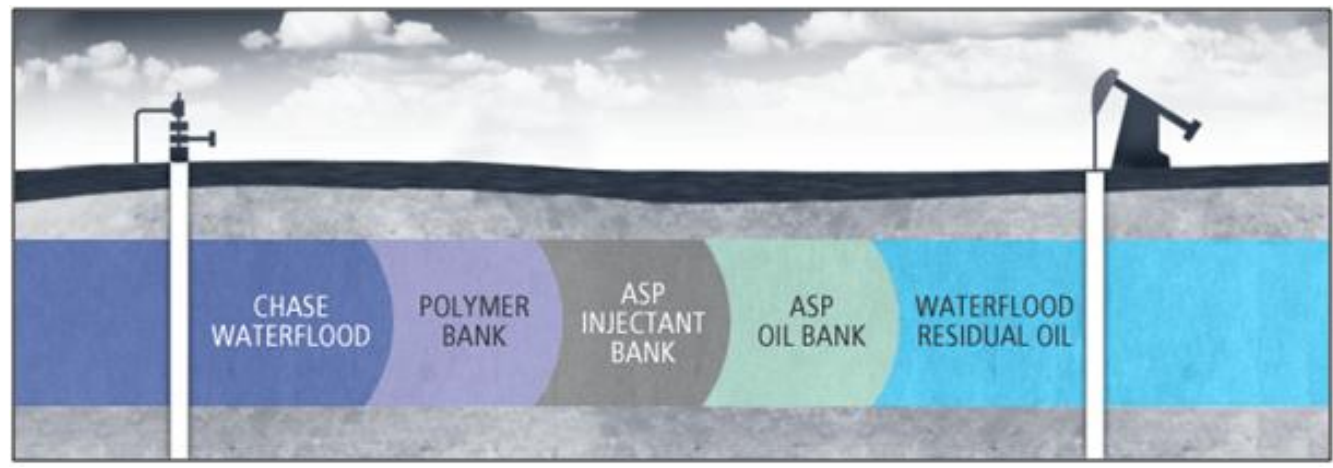

Figure6. Visualisation of ASP flooding process

Source: (http://zargon.ca/operations/oil-exploitation/tertiary-recovery/)

Despite the promising nature of ASP flooding, it has associated technical and economical limitations or risks with it application (Hou, et al., 2005; Zhang, et al., 2010). Technical issues associated with ASP primarily include

- formation damage due to scale formation as a result of the addition of alkali,

- scale build up in the injection and production equipment,

Difficulties in processing the produced fluids,

Economically, ASP flooding compared with polymer flooding only is costlier (Ru-Sen, et al., 2013). ASP flooding as well as other EOR techniques are capital and resource intensive and this is mainly due to the high cost of injectant (Kokal \& Al-Kaabi, 2010).

\subsection{Risk Associated with Asp Flooding}

Despite the favourable attributes of ASP achieved by the various synergies that exist between the chemicals when injected together, its implementation is without risk. ASP flooding is associated with various risk that has limited it widespread application. These risk include operational issues like low injectivity due to complete plugging of injection wells, degradation of polymer, pump failures, corrosion, difficulty in produced emulsion treatment and scaling issues (Weatherill, 2009; Bataweel $\&$ Nasr-El-Din, 2011). This section reviews some of these risks associated with ASP flooding.

\subsubsection{Precipitaion and Scaling Issues}

Operational problems caused by the formation of inorganic scales is one of the major risk associated with ASP flooding. Scaling issues in ASP flooding is caused by the alkaline injected. The injected alkaline causes an increase in the concentration of hydroxide ion ( $\mathrm{OH}-)$, carbonate ion (CO32-) and silicate ion (SiO32-). The increase in the carbonate ion concentration is due to the conversion of bicarbonate (HCO3-) into carbonate ion in the environment of high concentration of hydroxide ion. The increase in the concentration of silicate ion is also as a result of reaction between the injected alkaline and the formation minerals. Formation water contains divalent metal cations like calcium ion 
$(\mathrm{Ca} 2+)$ and magnesium ion $(\mathrm{Mg} 2+)$. These cations react with the anions formed by the injection of alkaline to form scales. Under certain $\mathrm{pH}$, temperature and pressure these scales precipitate and are deposited causing several problems in production facilities. Common inorganic scales encountered in ASP flooding are calcium and silicate scale.

Deposition of scale can occur within the reservoir, near the wellbore perforations, or in subsurface and surface facilities depending on the type of scale and reservoir fluid composition. They cause operational problems of varying level of severity (Umar \& Saaid, 2013). They cause formation damage as well as reducing tubing or pipe internal diameter resulting in reduction in production. Maintaining production in ASP flooding therefore involves inhibition of scale formation and removal of already deposited scales. This requires extra cost with affects the overall economics of the ASP project by increasing operational cost.

Precipitation of surfactant also occur during ASP flooding. This is caused by the presence of divalent cations in hard brines (Olaijire, 2014). This results in surfactant retention.

\subsubsection{Emulsification Problems}

As discussed earlier, emulsion is formed during ASP flooding process due to the reduction of IFT between oil and water by alkaline and surfactant. It was also discussed that this emulsion is made stable by polymer. Emulsification enhance oil recovery by improving both microscopic and macroscopic sweep efficiency either by entrainment or entrapment. Report on core flooding by Cheng, et al., (2001) reveals an incremental recovery of 5\% achieved by emulsification.

Three broad types of emulsion exist according to their structure; water-in-oil, oil-in-water and multiple or complex emulsion. Water-in-oil emulsion is more stable and common (most produced oil field emulsions). Due to the high viscosity of emulsion, it increases injection pressure and decreases water injection rate thereby decreasing liquid production rate. Also it causes transportation problems and it stable nature gives separation difficulties.

\subsubsection{Operational Issues}

There are several operational difficulties associated with ASP. This include pump failures caused by scale deposition which results in reduced pump life. Wang, et al., (2006) reported that the average work life of screw pump used for ASP flooding in Daqing was reduced to 97 days as compared to 375 days for polymer and 618 days for water flooding.

Also the viscoelastic property of polymer which aids recovery of oil from dead-end pores has adverse effect on fluid flow through pipelines (Sheng, 2013). A pulling force always try to pull fluid back into the main line whenever the fluid flows into a branch line at a $\mathrm{T}$ - section. Velocity increase in the main and branch lines increases this pulling force. There is velocity oscillation when triplex pump pumps and this velocity oscillation results in pump vibration.

There are problems also associated with logistics especially in offshore application. The ASP design itself is a complex process which requires analysis on oil, water and rock chemistry and reservoir heterogeneity as well. It implementation may not be feasibly in high temperature reservoirs, carbonates reservoirs and reservoirs with hard brine.

This means that both the technical and economic feasibility of ASP application depends on efficient use of the chemicals injected. In making ASP flooding more effective, a critical step is to deploy optimization which involves finding the optimal values of design variables that will maximize a particular performance measure (example, recovery efficiency, net present value) in a heterogeneous and multiphase petroleum reservoir (Zerpa, et al., 2005).

\subsection{Single Vs Multi Ojective Optimization}

Optimization deals with the study of problems in which one or more objectives that are functions of some real or integer variables must be either minimized or maximized (Bandyopadhyay \& Saha, 2013). Optimization process can be classified in to either single or multi-objective.

In single objective optimization, the main aim is to find the "best" solution, which is either the minimum or the maximum value of an objective function. This optimization process involves either aggregating all different objectives into a weighted function or converting all but one of the objectives into constraints. Limitations on this type of optimization approach include (Ngatchou, et al., 2005): 
- Only one solution is obtained with an aggregated function

- A priori knowledge about the relative importance of the objectives and the limits on those objectives that are converted into constraints is required.

- Difficulty in evaluating trade-offs between objectives.

- Unless the search space is convex, solution may not be attainable.

- On the contrary, multi-objective optimization which has conflicting objectives involves interaction among these incomparable objectives resulting in a set of compromised solution known as nondominated or Pareto-optimal set. There is no single optimal solution in this optimization approach. Considering more than one objective in an optimization process gives the following improvements (Savic, 2002):

- A wide range of alternatives are obtained for decision making.

- No a priori knowledge of the objectives required for the optimization process

- Models of problems generated by this optimization approach are more realistic.

Optimization is an indispensable process in many business management and engineering applications. These often involve satisfying incomparable or conflicting objectives. In most cases, converting all objectives into one has been done with the aim of finding the solution that minimizes or maximizes this single objective while maintaining the physical constraints associated with the system (Ngatchou, et al., 2005). Many heuristic algorithms have been developed for the process of optimization and one of the new algorithms is Particle Swarm Optimization (PSO). Over the past decade, promising results have been reported in the application of PSO in the single objective domain (Kennedy \& Russell, 1995; Zielinski \& Laur, 2006; Praveen \& Srinivasa Rao, 2014). This has resulted in the progression of its application in the multi objective domain.

\subsection{Particle Swarm Optimization Algorithm}

James Kennedy and Russell C. Eberhart (1995) first proposed the PSO algorithm for the optimization of continuous non-linear functions. It is a population - based search algorithm based on simulating the movement of birds within a flock aiming to find food.

The algorithm works by performing a search via a population (dubbed swarm) of candidate solutions (dubbed particles) that updates from generation to generation (Zhang, et al., 2015). To seek the optimal solution, the particles move around in the search space. Their movement are guided by their personal best (pbest) position and the global best (gbest) position in the search space. Each particle has:

$$
\begin{gathered}
\operatorname{pbest}(i, t)=\underset{k=1, \ldots, t}{\arg \min }\left[f\left(P_{i}(k)\right)\right], i \in\left\{1,2, \ldots . N_{p}\right\} \# \\
\operatorname{gbest}(t)=\underset{\substack{k=1, \ldots, N_{p} \\
k=1, \ldots, t}}{\arg \min }[f(P i(k))] \#
\end{gathered}
$$

Where $\mathrm{i}$ denotes the particle index, $\mathrm{N}_{\mathrm{p}}$ is the total number of particles, $\mathrm{t}$ is current generation number, $\mathrm{f}$ is the fitness function and $\mathrm{P}$ is the position.

At every generation, the velocity $(\mathrm{V})$ and position $(\mathrm{X})$ of each particle are updated by the equations 7 and 8

$$
\begin{aligned}
& V_{i}(t+1)=\omega V_{i}(t)+c_{1} r_{1}\left(\text { pbest }(i, t)-X_{i}(t)\right)+c_{2} r_{2}\left(\operatorname{gbes} t(t)-X_{i}(t)\right) \# \\
& X_{i}(t+1)=X_{i}(t)+V_{i}(t+1) \#
\end{aligned}
$$

Where $\mathrm{V}$ is velocity, $\omega$ is the inertia weight used to balance the global exploration and local exploitation, $\mathrm{r} 1$ and $\mathrm{r} 2$ are uniformly distributed random variables with a range of [0,1] and $\mathrm{c} 1$ and $\mathrm{c} 2$ are positive constant parameters called acceleration coefficients (Zhang, et al., 2015). To prevent particles from flying out of search space, an upper bound is set for the velocity either by "velocity cramping" or "constriction coefficient".

The inertia component (first part) of equation 7 represents the particle's previous velocity which gives it the necessary momentum for the particle to roam in the search space. The second part is known as 
the "cognitive" component; also represent the individual particle thinking of each particle. This part is what causes the particles to move towards their local best found so far. The third part is known as the "cooperation" component, represents the cooperative effect of the particles to find the global best (that is the optimum solution) (Zhang, et al., 2014).

The PSO algorithm works as follows; let $\mathrm{f}: \mathbb{R} n \rightarrow \mathbb{R}$, this is the objective function which must be minimized. A candidate solution is taken by this function as a vector of real numbers to produce a real number output as the value of the objective function of this candidate solution. The gradient of this function is either not known or difficult to compute. The aim is to find a global minimal that is a solution "a" for which $\mathrm{f}(\mathrm{a}) \leq \mathrm{f}(\mathrm{b})$ for all $\mathrm{b}$ in the search-space. For the purpose of maximization, the function needs to be negated (that is $\mathrm{g}=-\mathrm{f}$ ). The basic PSO algorithm is shown on Figure 7.

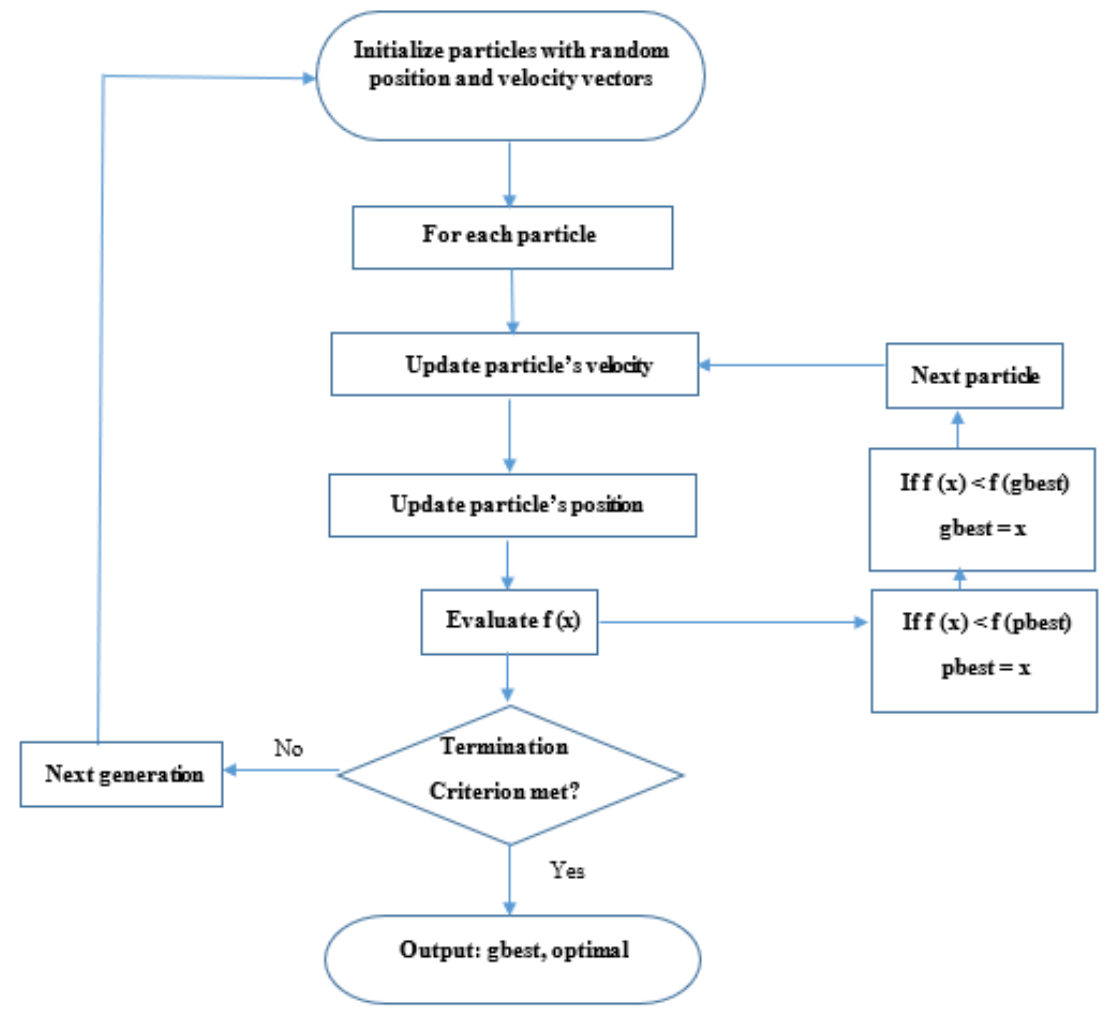

Figure7. A schematic of PSO algorithm

\subsubsection{Multi-Objective Particle Swarm Optimization}

The extension of the application of PSO from single to multi objective has been a natural progression. This is due to its relative simplicity, similarities in structure to evolutionary algorithms (EA) (such as the presence of a population searching for optima and information sharing between the members in the population) and the promising results obtained in the single objective optimization domain (Alvarez-Benitez, et al., 2005; Reyes-Sierra \& Coello Coello, 2006; Esquivel \& Cagnina, 2008).

The multi-criteria nature of problems with conflicting multiple objectives calls for redefinition of optimality of solutions. In multi-objective optimization, the concept of Pareto optimality proposed by Vilfredo Pareto in 1986 is used. Before the changes in PSO algorithm for multi-objective optimization will be reviewed, it is vital to review the concept of optimality and some definitions regarding dominance.

The multi-objective optimization problem can be defined as (Alvarez-Benitez, et al., 2005):

minimize $\vec{f}(\vec{x}):=\left[f_{1}(\vec{x}), f_{2}(\vec{x}), \ldots, f_{k}(\vec{x})\right] \#$

subject to:

$g_{i}(\vec{x}) \leq 0 \quad i=1,2, \ldots, m \#$

$h_{i}(\vec{x}) \leq 0 \quad i=1,2, \ldots, p \#$ 
Multi-Objective Function Approach of Optimizing Alkaline-Surfactant Polymer Flooding Performance using Particle Swamp Algorithm

Where $\vec{x}=\left[x_{1}, x_{2}, \ldots, x_{n}\right]^{T}$ is a vector of decision variables, $f_{i}: \mathbb{R}^{n} \rightarrow \mathbb{R}, i=1, \ldots, k$ are objective functions and $g_{i}, h_{i}: \mathbb{R}^{n} \rightarrow \mathbb{R}, i=1, \ldots, m, j=1, \ldots, p$ are constraints functions of the problem?

Definition 1(Pareto Dominance): Given two decision vectors $\vec{x}, \vec{y} \in \mathbb{R}^{k}, \vec{x}$ dominates $\vec{y}$ (denoted by $\vec{x} \prec \vec{y}$ ) if $\vec{x} \leq \vec{y}$ that is $x_{i} \leq y_{i}$ for all $i=1, \ldots, k$ and at least for one $i, x_{i}<y_{i}$.

Definition 2 (Pareto Optimality): A vector of decision variables $\vec{x}^{*} \in \mathcal{F} \subset \mathbb{R}^{n}$ (F is the feasible region) is Pareto-Optimal if it is not dominated by any vector $\vec{x}$ in the feasible region.

Definition 3 (Pareto Optimal Set): The Pareto optimal set denoted by $\mathcal{P}^{*}$ of a given multi-objective problem is defined as:

$\mathcal{P}^{*}=\{\vec{x} \in \mathcal{F} \mid \vec{x}$ is Pareto - optimal $\}$

Definition 4 (Pareto Front): The Pareto front denoted by $\mathrm{P} \mathcal{F}^{*}$ of a given multi-objective problem and a Pareto optimal set is defined as:

$\mathcal{P F}^{*}=\left\{\vec{f}(\vec{x}) \in \mathbb{R}^{k} \mid \vec{x} \in \mathcal{P}^{*}\right\}$

It is desirable to generate several non-dominated solutions in one run considering the populationbased nature of PSO. So as in any other EA, the main issues associated with the MOPSO are: (Coello Coello et al., 2002) as cited in (Reyes-Sierra \& Coello Coello, 2006)

- Selection of particles to be used as leaders given preference to non-dominated solutions over dominated solutions.

- Retaining the non-dominated solutions from all generations to be reported at the end of the search process and not reporting only non-dominated solution from only the final generation. These solutions must as well be well spread along the Pareto front.

- Maintaining diversity in the swarm to avoid convergence to a single solution.

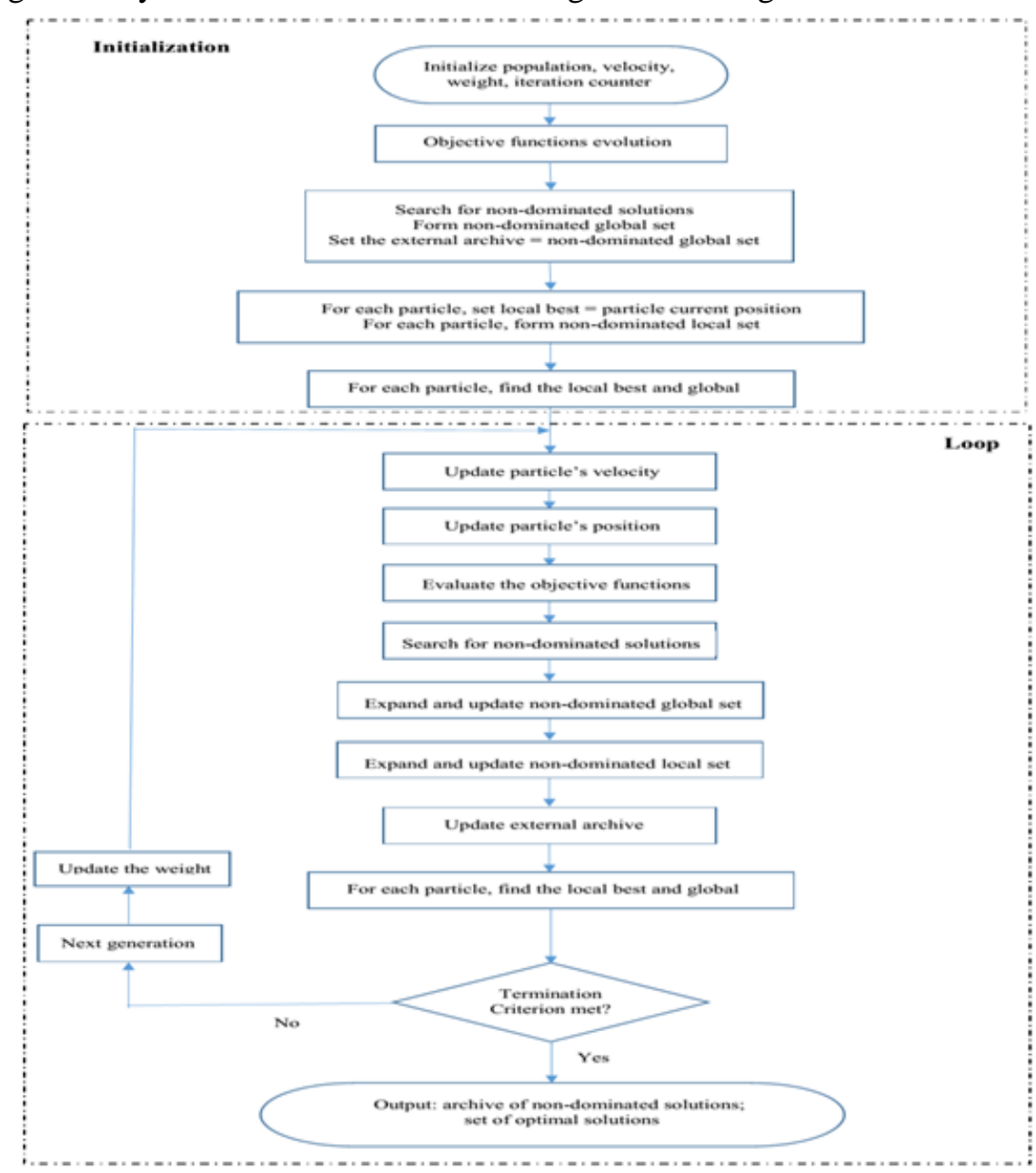

Figure8. A schematic of MOPSO algorithm

Source: (Abido, 2009) 
As discussed in the previous section, in single-objective particle swarm optimization (SOPSO), movements of particles are guided by a chosen leader (personal best and global best solution). In MOPSO there are several leaders from which one has to be chosen to update a particle's position. These leaders are the non-dominated solutions found so far and are stored in a place different from the swarm. An external archive is therefore needed in MOPSO to store the non-dominated solution.

It is obvious that there should be modification in the original scheme to extended PSO to the multiobjective domain. Figure 8 shows how the general algorithm for MOPSO works. A comparison of the basic steps in SOPSO and MOPSO is also presented on Table 1.

Table1. Comparison between SOPSO and MOPSO algorithm

Source: (Patil \& Dangewar, 2014)

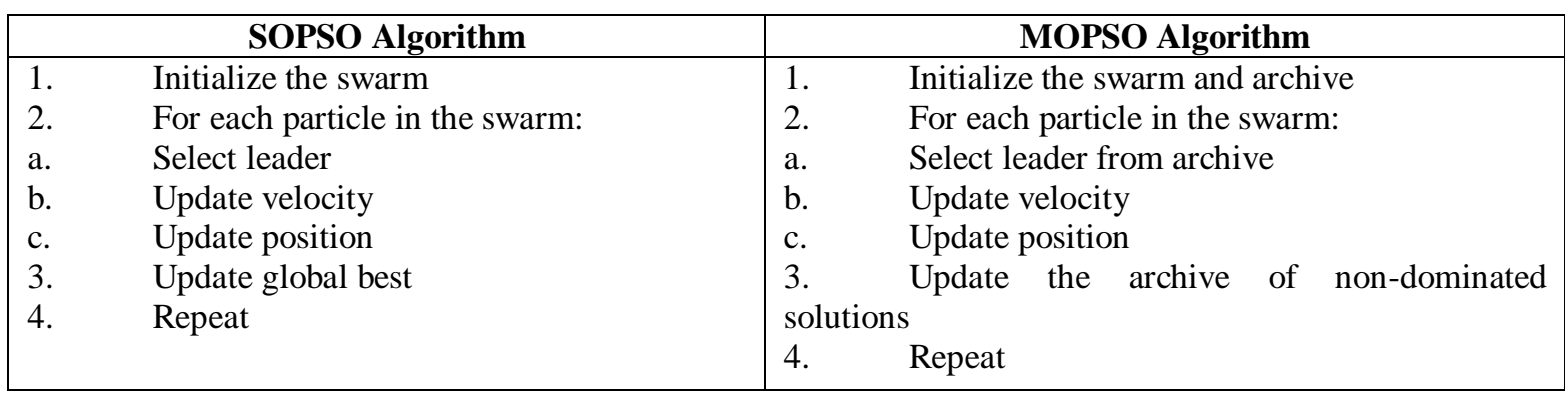

\subsection{Problem Statement}

The main aim of ASP flooding as well as other EOR techniques is to increase oil recovery (that is reducing residual oil saturation) beyond that achieved from pressure maintenance by water or gas injection and water flooding. After conventional water flooding, the residual oil remains as discontinuous phase in the reservoir trapped by capillary forces (Zerpa, et al., 2005). This oil left within the reservoir is likely to be around two third of the OOIP. ASP flooding has been proved by laboratory experiments, pilot projects as well as large-scale applications to be very effective in reducing this residual oil saturation. This has been achieved by the combined effect of reducing IFT to ultralow value and reducing mobility ratio between oil and water.

Nevertheless, the implementation of ASP flooding is intimately tied to the overall economics involved. As stated already, ASP flooding is capital and resource intensive and expensive and this is mainly due to the cost of the chemicals injected. Therefore, by optimizing the formulation, the chemical usage in the ASP system can be reduced significantly (Hongfu, et al., 2003)

Also associated with ASP flooding is the cost in handling scale problems. Scale formation is a serious problem in the oil and gas industry and they cause formation damage near the wellbore area leading to reduced productivity and injectivity. They form within perforation, casing, tubing, and in surface facilities. Factors that facilitates scale precipitation include temperature, pressure, the presence of divalent cation and variation in $\mathrm{pH}$. Among these and other factors, $\mathrm{pH}$ variation plays the major role in scale formation. Scale precipitation and deposition in production facilities cause excessive loss of production, increased average work over periods and hence leads to low commercial effectiveness (Umar \& Saaid, 2013). In ASP flooding, pH variation is caused by the addition of Alkaline.

\subsection{Aims and Objectives}

The main aim of this study is therefore to obtain a set of optimum ASP designs that give maximum oil recovery efficiency (FOE) whiles minimizing the total chemical usage as well as the final $\mathrm{pH}$ to mitigate scale problem and it associated cost. The model parameters that the study seeks to optimize include;

- Number of cycles in the entire ASP campaign

- The duration of the EOR process (that is the ASP main slug and polymer post-flush)

- The duration for the polymer post flush

- Concentration of Alkaline in ASP slug

- Concentration of Surfactant in ASP slug

- Polymer concentration in ASP slug and polymer post-flush

International Journal of Petroleum and Petrochemical Engineering (IJPPE)

Page | 30 
The objectives of this study are therefore to:

- Define a multi-objective optimization problem by specifying three conflicting objective functions. The objective functions are FOE, Total chemical injected and the concentration of alkaline in produced fluids which is converted into the final $\mathrm{pH}$.

- Use Multi-Objective Particle Swarm Optimization (MOPSO) to determine a set of optimum ASP designs (non-dominated particles or Pareto set) deploying Pareto dominance.

- Examine the variation of particles (ASP designs) with the three objective functions in a threedimensional sense.

- Find the relative contribution of the various ASP design parameters to the first objective function (FOE).

- Analyse the overall economics of the individual optimum ASP designs in the Pareto set to determine their economic viability.

\subsection{Justification or Significance of Study}

This optimisation process applied to real field situation can aid in decision making as to whether applying ASP flooding on an already depleted field will be economically viable or not. It can also aid in obtaining an optimum ASP formulation that can improve recovery whiles mitigating the limitations associated ASP flooding.

\section{REVIEW OF LITERATURE}

Determining an optimum design for ASP flooding just like most optimization problems in the real world often require that several conflicting objectives have to be traded against each other while seeking a viable solution to the given problem (Esquivel \& Cagnina, 2008). Several studies have been done on finding the optimal design for ASP recovery processes, these among many others include;

Estimation of optimal values for a set of design variables (slug size/ concentration of chemical agent) to maximize the cumulative oil recovery from a multiphase and a heterogeneous system subjected to ASP flooding (Zerpa, et al., 2005). Previously reported works in this area using reservoir numerical were limited to sensitivity analyses at core and field scale levels because the objective functions involved in formal optimization are computationally expensive to evaluate. This study therefore deployed a surrogate-based optimization methodology to overcome this limitation.

The use of surrogate-base analysis/optimization to establish the relative contribution of design variables to the performance measure (net present value /cumulative oil recovery) variability using a limited number of computationally expensive reservoir simulations (Carrero, et al., 2007). This study presented an efficient global sensitivity approach based on Sobol's method and multiple surrogates (i.e. Polynomial Regression, Kriging, Radial Base Function, and a Weighted Adaptive Model). The multiple surrogates were used to address the uncertainty in the analysis derived from plausible alternative surrogate-modelling schemes.

The determination of optimum ASP flooding parameters (chemical concentration, length of each type of injection within a cycle) by deploying optimization program (Covariance Matrix Adaptation Evolution Strategy Algorithm) which give a high recovery efficiency but at a lower cost (Gubashov, 2015). This work involves single objective optimization. That is, all the objective functions were aggregated into single objective function which he termed "net FOE" for the optimization process.

In the aggregation process, he converted the cost of each chemical injected into an FOE equivalent by the formula (for alkaline);

Cost of alkaline (as fraction of OOIP) $=\frac{\text { FTIALK }}{8.36 \times 10^{8}} \#$

Where FTIALK is the total alkaline injected in lbs and the constant involves the price of oil, cost of alkaline and the oil in place value.

To include the third objective (final $\mathrm{pH}$ ), knowledge on scale formation due to this $\mathrm{pH}$ was required. This third objective was converted into the total production that will be lost for five days as a fraction of the oil in place. This production lost for five days was based on the assumption that in order to restore production to its initial level, five days of work over will be done to remove the scale during which the wells will be shut. 
Gubashov's approach obtained great findings on optimization in ASP flooding nevertheless; it has the short comings of single objective optimization as discussed earlier; a prior knowledge on the objectives and simplifying assumptions that makes the model unrealistic.

In this study, the multi objective approach is used where an optimal set of solutions is obtained. This allows for better understanding of chemical utilization while trying to achieve a better recovery efficiency. In addition, ASP designs that mitigate scale formation can be obtained.

\section{Methodology}

The study deployed, HistMatMPI developed by Ilya Fursov, an in-house program that allows solving optimization problems using Eclipse reservoir simulator. Files used for the optimization process include;

1. Eclipse dataset from the Harold model which was used for simulating the ASP flooding process.

2. Additional files for parameterizing the model and defining the objective functions

Output files from running HistMatMPI were in text format. Various plots were made from these out files using gnuplot. Data from these output files were also used as inputs for the economic model in Microsoft excel.

\subsection{Optimization Process}

In this study, a multi-objective optimization problem was defined by specifying three conflicting objective functions. The objective functions are

1. Field Oil Efficiency (FOE),

2. Total chemical injected and

3. The concentration of alkaline in produced fluids which is converted into the final $\mathrm{pH}$.

Multi-Objective Particle Swarm Optimization (MOPSO) was used to determine a set of optimum ASP designs (non-dominated particles or Pareto set) deploying Pareto dominance. The variation of particles (ASP designs) were examined with the three objective functions in a three-dimensional sense and the relative contribution of the various ASP design parameters to the oil recovery efficiency was also examined. The overall economics of the individual optimum ASP designs in the Pareto set were finally analysed to determine their economic viability.

\subsection{Model Parameter Space}

In the execution of the ASP flooding process, large volumes of the chemicals are to be injected. For efficient execution of the flooding process, the entire duration of the process is subdivided into cycles. In a cycle, all the chemicals are injected one after the other as shown in Figure 9. The entire flooding process can also be divided into the EOR part and the water injection part. The EOR part also involves the injection of the ASP slug and injection of polymer post-flush.

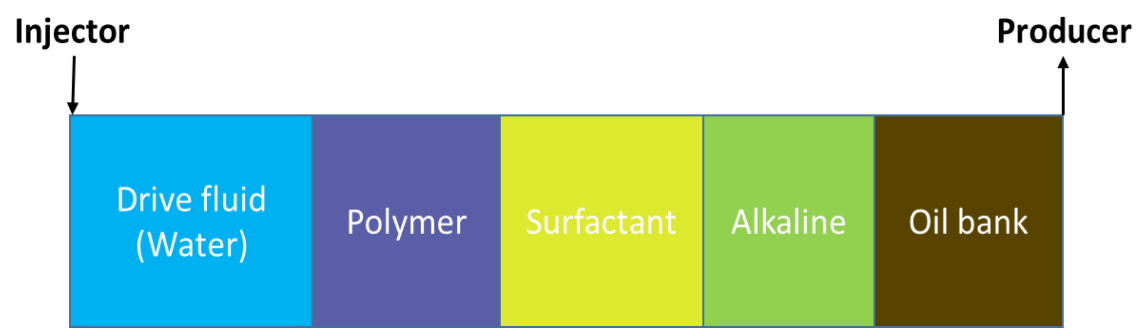

Figure9. Order in which chemicals are injected in ASP flooding

In the optimization process, the model characterizes the ASP flooding based on several design parameters. These model parameters are based on the various part of the flooding process described above (Figure 10). These parameters include:

- The number of cycles $(\mathrm{N})$

- Duration of the EOR within a cycle (Lambda)

- Duration of polymer post-flush in the EOR (Mu) 
Multi-Objective Function Approach of Optimizing Alkaline-Surfactant Polymer Flooding Performance using Particle Swamp Algorithm

- Alkaline concentration for ASP

- Surfactant concentration for ASP

- Polymer concentration for ASP and the polymer post-flush

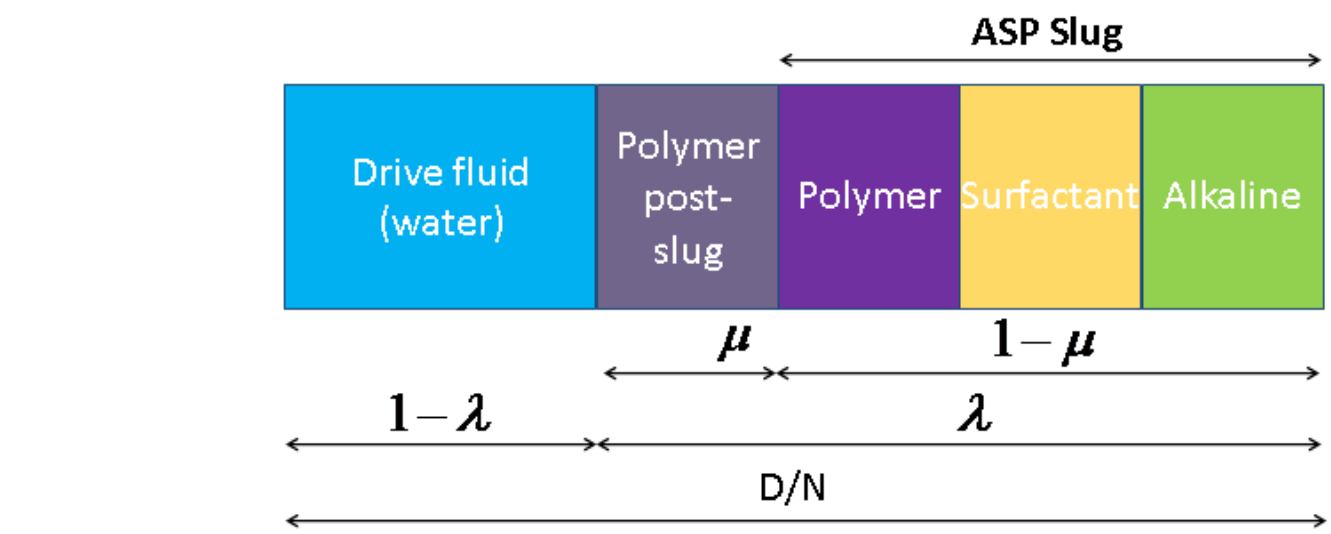

\subsubsection{Number of Cycle}

In the model, the duration for the entire ASP flooding process D is 2000days.This parameter in the model explores the effect of dividing this duration into $\mathrm{N}$ number of cycles. In the optimization process, the minimum and maximum bound of this parameter was set to 1 and 20 respectively.

\subsubsection{Lambda}

This parameter characterizes the duration of the EOR part of the flooding process as a fraction of the entire duration in a cycle. This implies that

Duration of EOR in days $=\frac{D}{N} \times \lambda \#$

Duration of water injecting in days $=\frac{D}{N} \times(1-\lambda) \#$

The minimum and maximum bound of this parameter is set to 0 and 1 respectively

\subsection{3. $M u$}

This parameter represents the fraction of the duration for EOR for polymer post-flush with minimum and maximum bound also set to 0 and 1 respectively. Therefore:

Duration of ASP in days $=\frac{D}{N} \times \lambda \times(1-\mu) \#$

Duration of polymer post - flush in days $=\frac{D}{N} \times \lambda \times \mu \#$

\subsubsection{Asp Chemical Concentrations}

The concentration of the chemicals injected is characterized by the last three parameters of the model. The limits of these parameters are set as 0 to $6.6 \mathrm{lb} / \mathrm{stb}$ for concentration of alkaline in ASP, 0 to $1.4 \mathrm{lb} / \mathrm{stb}$ for concentration of surfactant in ASP and 0 to $7.1 \mathrm{lb} / \mathrm{stb}$ for concentration of polymer in ASP and polymer post-flush.

Table 2 present summary of the limits and initial values of the model parameters used for the optimization. All parameters were made active in the optimization process that means during the optimization process values of these parameters can be varied within the set limits

Table2. Summary of model parameter limits and initial values

\begin{tabular}{|c|c|c|c|}
\hline Parameters & Minimum & Maximum & Initial \\
\hline $\mathrm{N}$ & 1 & 20 & 7 \\
\hline Lambda & 0 & 1 & 0.9 \\
\hline $\mathrm{Mu}$ & 0 & 1 & 0.08 \\
\hline Alkaline concentration $(\mathrm{lb} / \mathrm{stb})$ & 0 & 6.6 & 4.4 \\
\hline Surfactant concentration $(\mathrm{lb} / \mathrm{stb})$ & 0 & 1.4 & 0.95 \\
\hline Polymer concentration $(\mathrm{lb} / \mathrm{stb})$ & 0 & 7.1 & 2 \\
\hline
\end{tabular}


Multi-Objective Function Approach of Optimizing Alkaline-Surfactant Polymer Flooding Performance using Particle Swamp Algorithm

\subsection{Economic Analysis}

The overall economics of ASP flooding is very vital in determining whether it will be implemented or not. This is because the extra oil recovered from the flooding process has to be enough to offset all incurred cost and generate profit as well.

Nevertheless, in this economic analysis, the main aim is to investigate the economic efficiency of the all the solutions generated by the optimization process as the optimum alternatives to ASP flooding design.

Assumptions made in this economic analysis to simplify the economic model is as follows:

- The assumed oil price was based on the current oil price, but its value was halved to compensate for taxes and other cost such as facility cost and operational cost. The main cost included in this economic model is the cost of the chemicals.

- It is assumed that production rate will be constant through the ASP flooding process

- Constant operating expenditure (Opex) based on the total cost of chemical injected is assumed.

- A constant inflation rate is also assumed. The table below shows the inputs for the net present value (NPV) calculation (Appendices).

Table3. Economic inputs for NPV calculation

\begin{tabular}{|l|l|}
\hline Oil price $(\$ / \mathrm{bbl})$. & 40 \\
\hline Cost of alkaline $(\$ / \mathrm{lb})$ & 0.68 \\
\hline Cost of surfactant $(\$ / \mathrm{b})$ & 1.5 \\
\hline Cost of polymer $(\$ / \mathrm{bbl})$. & 1.81 \\
\hline Inflation rate $(\%)$ & 3 \\
\hline Discount rate $(\%)$ & 10 \\
\hline
\end{tabular}

\section{RESULTS AND DISCUSSION}

\subsection{Optimization Results and Discussion}

The multi-objective optimization process found 92 non-dominated solutions using Pareto dominance. Figure 11 shows the distributions of the Pareto-optimal set and the set of particles in all generations within the objective function space. Two different analyses were made based on this distribution. The first was to analyse the efficiency of the total chemical usage in the ASP flooding process. The second was to analyse the effect of the final $\mathrm{pH}$ on the recovery efficiency. The final $\mathrm{pH}$ depends on the concentration of alkaline in the produced fluids.

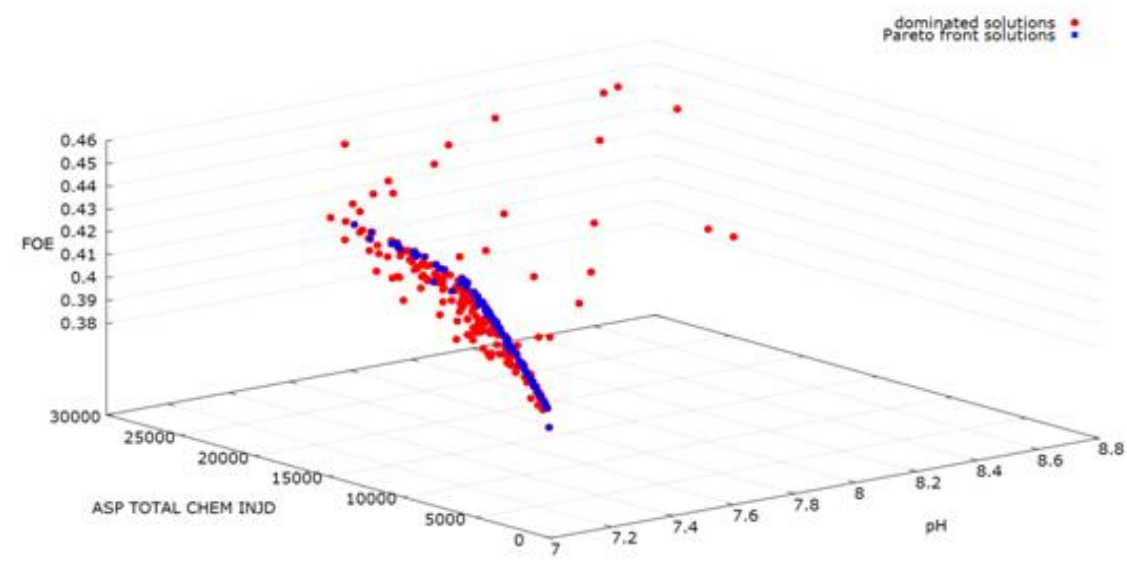

Figure11. Particles in the Objective Functions Space

For the efficiency of the total chemical used, the analysis was based on the shape of the Pareto front. Existence of two slopes is patent from careful observation of the Pareto front. The first slope, which is steep, ranges from an FOE of about 0.396 to 0.437 with ASP total injected chemicals of about 0.23 to $4.9 \times 106 \mathrm{lb}$. The steepness of this first slope indicates that less increment in the total chemical injected results in relatively large increase in the recovery efficiency. The second slope is gentle with 
FOE ranging from 0.441 to 0.453 with ASP total injected chemical ranging from 5.6 to $13.3 \mathrm{x} 106 \mathrm{lb}$. This means that beyond the point where the slope changes from being steep to gentle, more chemicals need to be used to increase recovery efficiency.

Analysis on the effect of the final $\mathrm{pH}$ on recovery efficiency was based on the position of the Pareto front in the objective function space. All the Pareto optimal set had a final $\mathrm{pH}$ of approximately 7 and there is clustering in the dominated solutions on a final $\mathrm{pH}$ of 7 . Figure 12 is a multi-plot showing the variation between pairs of objective functions in a 2 dimensional sense with a colour bar for the third objective function.
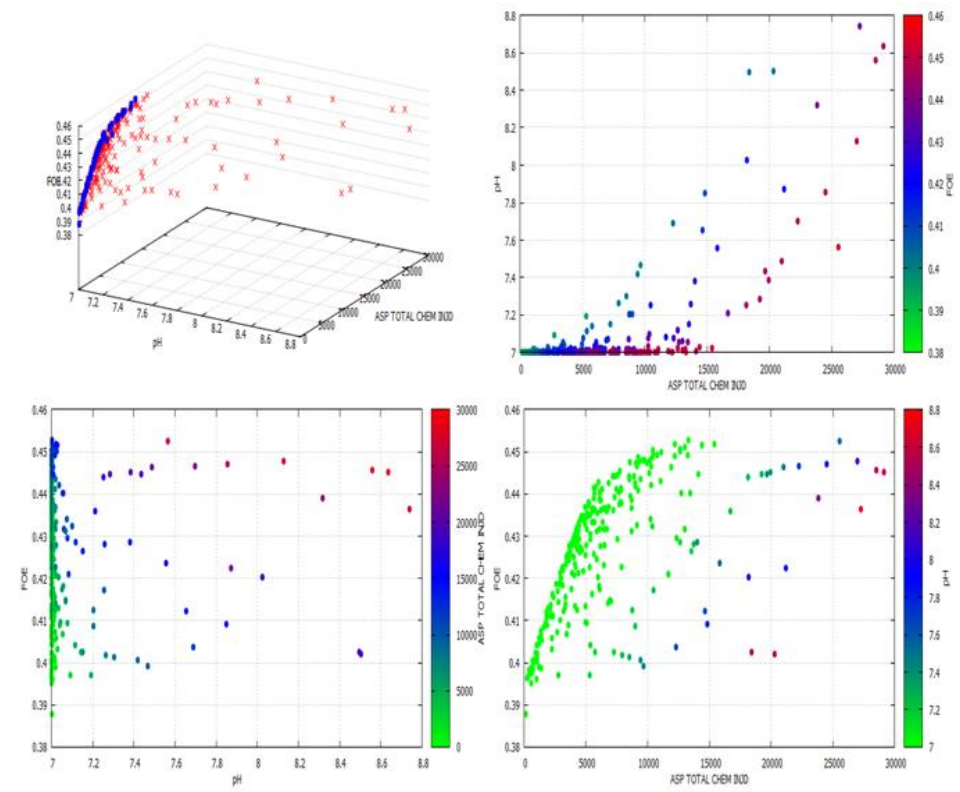

Figure12. Multi-plot of Particles' distribution in Objective Functions Space

On the multi-plot, the plot of FOE against $\mathrm{pH}$ has a clustering of solutions on $\mathrm{pH}$ of 7 . Also on the plot of FOE against total chemical injected with a colour scale of $\mathrm{pH}$, has most of the points indicating a $\mathrm{pH}$ of 7 (green). This means that low alkaline concentration is vital for optimum ASP design.

\subsection{Effect of Design Parameters on ASP Design}

A critical step for the optimal design and control of ASP recovery processes is to find the relative contributions of design variables such as, slug size and chemical concentrations, in the variability of given performance measures (example FOE) (Carrero, et al., 2007). Analysis on the effect of the various design parameters on the efficiency of the ASP flooding therefore showed the results presented in this section. This was to investigate the significance of these parameters in ASP design. This analysis was on only solutions in the Pareto Optimal Set.

\subsubsection{FOE vs LAMBDA}

Figure 13 shows a general trend of FOE increasing with increasing duration of EOR in a cycle. On the plot, the EOR duration axis ranges from 0.5 to 1 indicating that optimum ASP design requires the duration for EOR chemical injection to be always more than

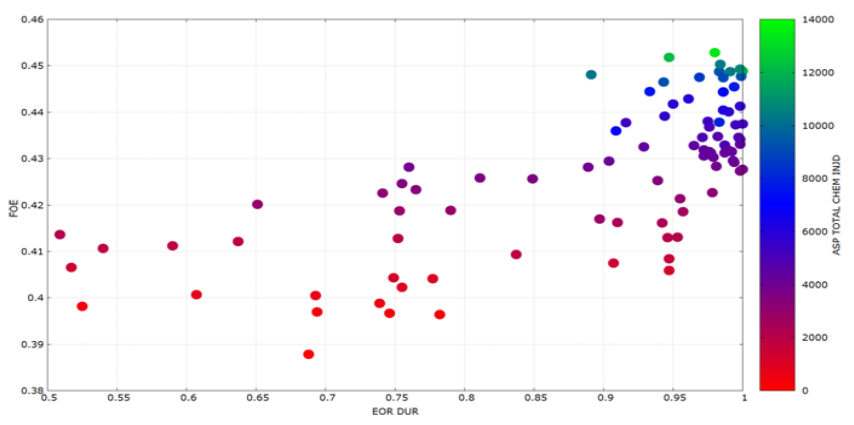

Figure13. Plot of FOE vs EOR Duration 
half of the duration per cycle. There is also a clustering of points between 0.95 and 1 . This shows that for efficient ASP design the more significant part of the project within a cycle is the injection of ASP slug and polymer post-flush. The figure 13 even shows scenarios without injection of water as drive fluid, yet a high recovery achieved. The other observation from this analysis is the increase in the Total chemical injected as EOR duration (as fraction of duration in a cycle) increases which is as would be expected.

\subsubsection{FOE vS $M U$}

Further analysis involved the investigation of the duration of the ASP slug injection and the duration for polymer post-flush.

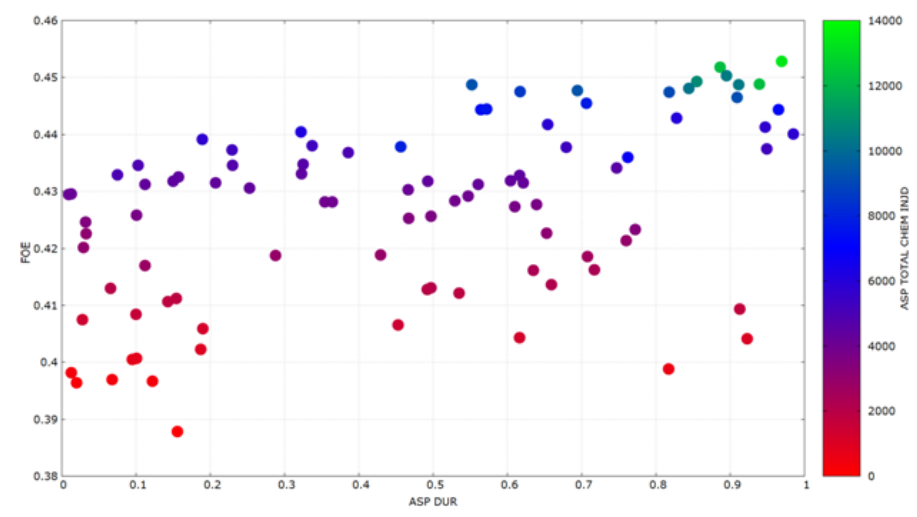

Figure14. Plot of FOE vs ASP Duration

From Figure 14, the points seem scattered but with a closer observation, a trend of FOE increasing with increasing ASP duration is apparent.

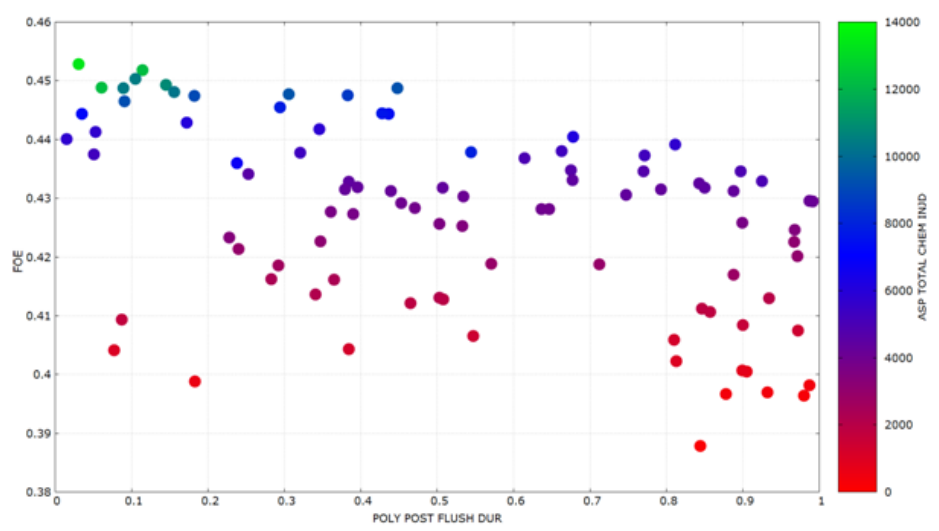

Figure15. Plot of FOE vs Duration of Polymer Post-flush

Figure 15 on the other hand shows a trend of decreasing FOE with increasing polymer post-flush duration. Combining the trend on the two figures, it is apparent that the duration for injecting the ASP slug is a very significant part of the ASP flooding design.

\subsubsection{FOE vs Chemical Concentration}

Analysis on the effect of the concentration of the various chemicals on the recovery efficiency showed intriguing results (Figure 16) that is very vital in the formulation of ASP slug. Considering the plot of FOE against the concentration of alkaline, varying recovery efficiencies were achieved with low alkaline concentration $(0-0.04 \mathrm{lb} / \mathrm{stb})$. Only few solutions showed high alkaline concentration and all these solutions had very low recovery efficiency. This can be attributed to the final $\mathrm{pH}$, which causes the formation of scale when high. The surfactant concentration showed an increasing trend in recovery effeciency with increasing surfactant concentration but this trend is not very patent. The polymer concentration on the other hand showed a profound increasing trend in recovery efficiency with increasing polymer concentration. Polymer is therefore very important in the ASP slug formulation but while increasing its concentration, the overall economics should be considered since it is the most expensive among the chemicals injected. This leads to the economic analysis of the ASP flooding process in the next chapter. 

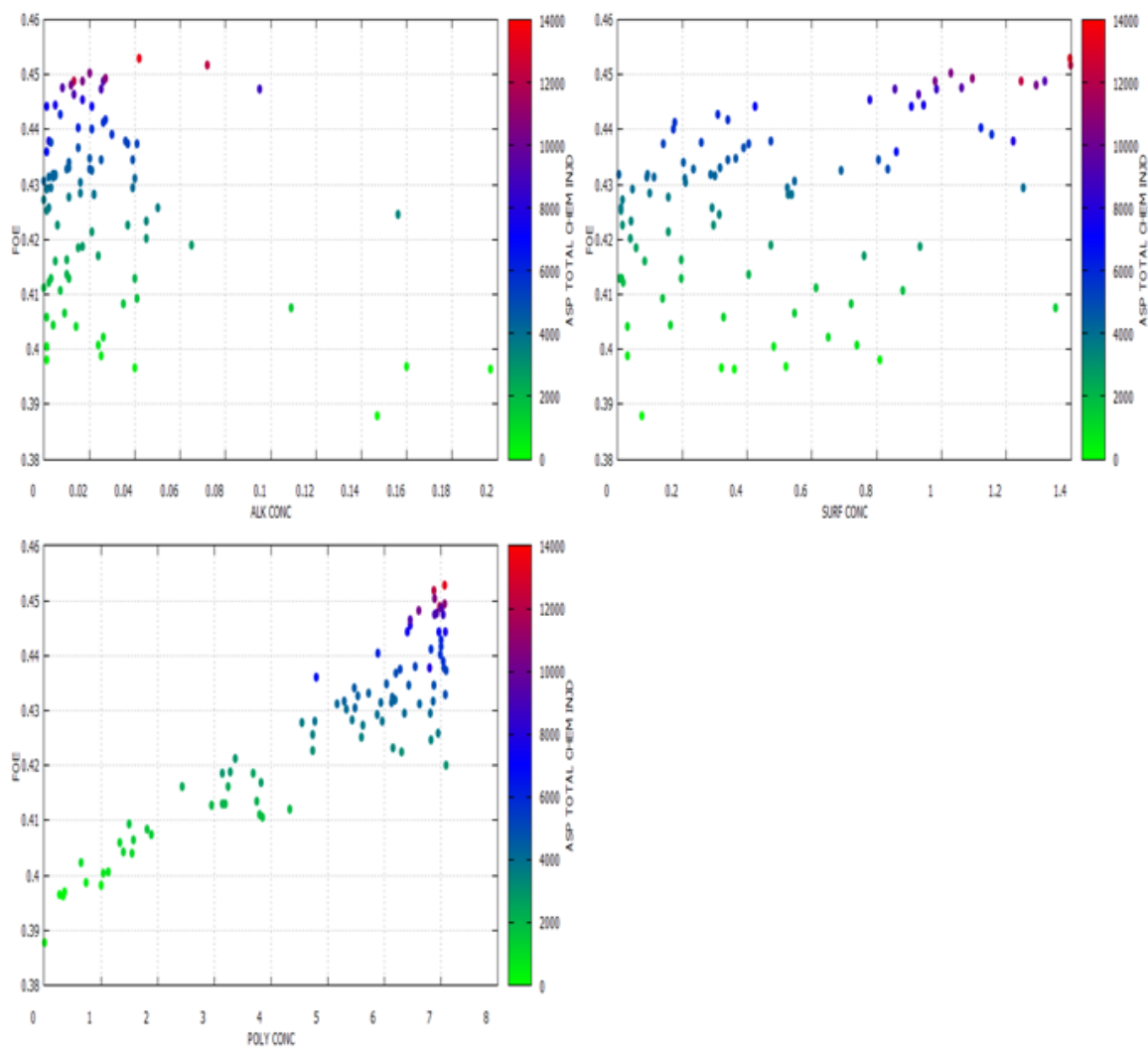

Figure16. Multi-plot of FOE vs Chemical Concentrations

\subsection{Economic Results and Discussion}

The results from the economic analysis confirmed the inference made from the shape of the Pareto front in the previous chapter. Figure 17 shows a plot of NPV against FOE and it can be seen from this plot that, the maximum NPV achieved by increasing recovery efficiency is around the same FOE value on which there was a change in the slope of Pareto front from steep to gentle. The reduction in NPV after this FOE value can therefore be explained as due to fact that more chemicals are being utilized to achieve incremental oil beyond this point.

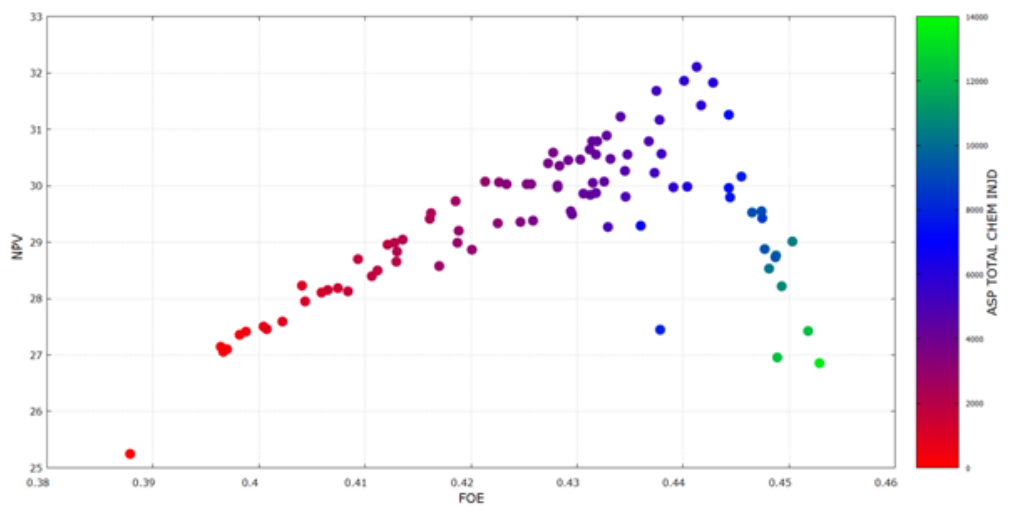

Figure17. Plot of $N P V$ vs FOE

\subsubsection{Price Sensitivity}

Further analysis includes investigating the effect of oil price volatility on the implementation of ASP flooding as an EOR method. The base case oil price was therefore halved and doubled to simulate situations of very low oil price and high oil price respectively.

In the low oil price situation (Figure 18), the NPV decreases gently with an attempt to achieve incremental oil until the FOE value beyond which efficiency of chemical injected reduces. Beyond this FOE value, incremental oil recovery results in rapid decrease in NPV. This shows how ASP flooding would not be favourable in low oil price situation. 


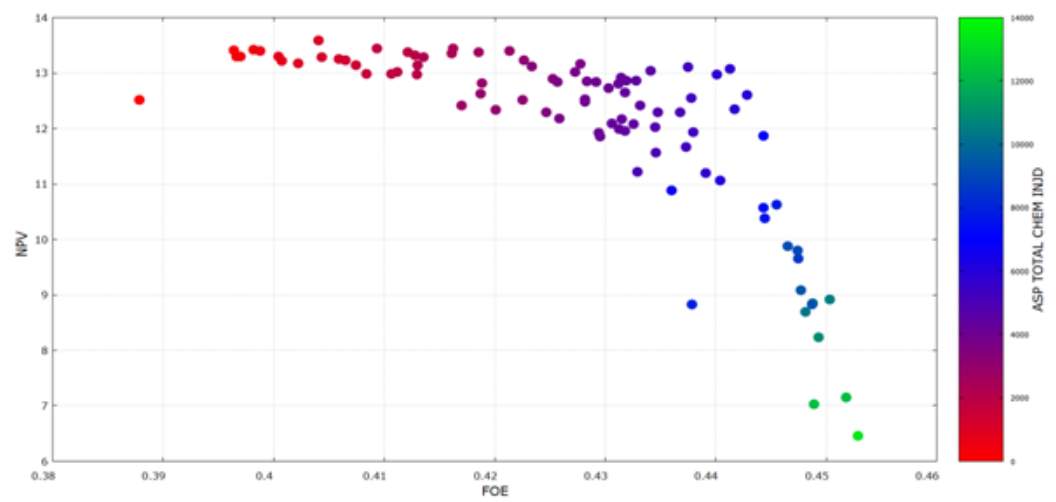

Figure18. Plot of NVP vs FOE in low oil price situation

The high oil price situation resulted in a favourable NPV increase as incremental oil recovery is achieved. Despite the maximum NPV being around the same FOE value as the base case oil price, it can be seen from the trend that with more favourable oil price situation, incremental oil beyond this FOE value can be economically viable.

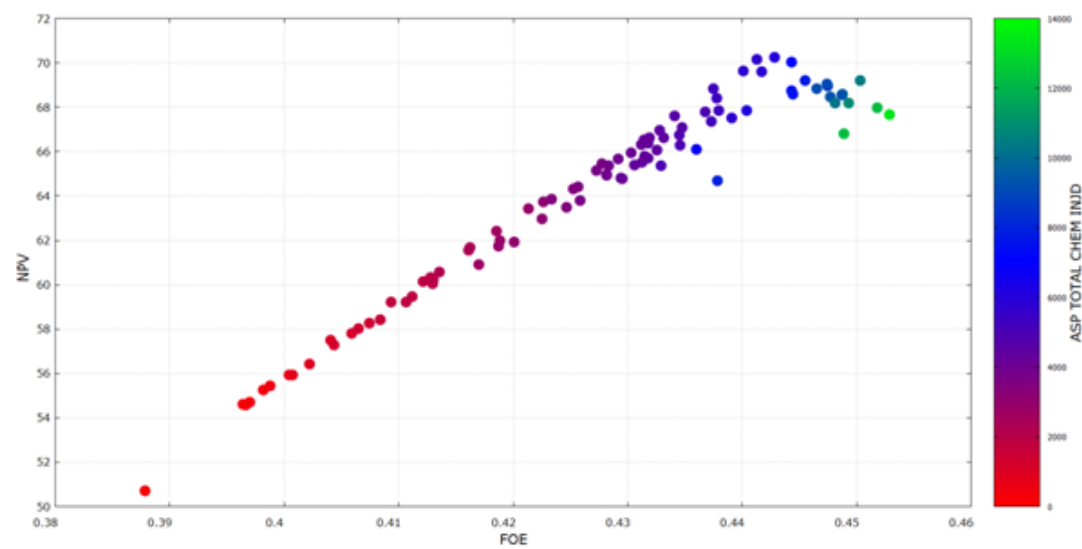

Figure19. Plot of NPV vs FOE in a high oil price situation

\section{CONCLUSION OF FindingS}

- From the optimization results, it can be concluded that ninety two (92) ASP flooding design alternatives are available as optimum designs from which a decision can be made with further analysis as to which design should be implemented.

- From the analysis made on the optimal set of solutions, it can be concluded that an FOE of $45.29 \%$ (that is incremental recovery of 17.29\%) is achievable with ASP flooding. Nevertheless, efficiency of the total chemical injected decreases beyond an FOE of $44.19 \%$.

- The optimization process showed that optimum ASP designs can be achieved with low concentration of alkaline in the ASP slug to mitigate the formation of scales.

- Analysis on the effect of the design parameters on the recovery efficiency showed that, in the implementation of ASP flooding, the duration for injecting the ASP slug is the most important among the injected fluids.

- Also in the formulation of ASP slug, polymer is the most important chemical and increasing it concentration results in increase recovery efficiency yet it is the most expensive chemical among the chemicals in the ASP slug. Therefore, increasing its concentration should be traded against the total cost of the chemicals injected hence the overall economics of the ASP flooding project.

- It was confirmed from the economic analysis that indeed beyond $44.19 \%$ FOE, the overall economics of the ASP flooding becomes unfavourable due to more chemicals being used.

- Price sensitivity analysis showed that like all other EOR methods, high oil price situation is needed for the implementation of ASP flooding to be favourable despite it being a cost effective EOR method. Also, with favourable oil price situation, recovery beyond the $44.19 \%$ can become economically viable. 
Multi-Objective Function Approach of Optimizing Alkaline-Surfactant Polymer Flooding Performance using Particle Swamp Algorithm

\section{APPENDIX}

\section{A. Economic Impuct Calculation}

\begin{tabular}{|c|c|c|c|c|c|c|c|}
\hline \multirow{2}{*}{$\begin{array}{c}\text { FOAP } \\
\text { FOE (Ob;s0) }\end{array}$} & \multirow{2}{*}{$\begin{array}{l}7,585,582 \text { s:b } \\
0.442851\end{array}$} & \multicolumn{4}{|c|}{ Capex (Cost of Chemicals) } & \multirow[b]{2}{*}{$\operatorname{Cost}(\$ / \mathrm{lb})$} & \multirow[b]{2}{*}{ TOTALCHEM } \\
\hline & & Chemical & $\operatorname{con} 0(x 3 . \times 5)$ & Conc Fraction & TOTAL CHEM & & \\
\hline Incremental foE & 0.162851 & & $\mathrm{lb} / \mathrm{stb}$ & fraction & INID (10*3 ID) & & cost (Smallion) \\
\hline FOPT ASD & $1235319.6 \mathrm{stb}$ & 0.007 & 0.007 & 0.276 & 1659.79224 & 0.68 & 1.128658723 \\
\hline ave production rate & $623.8938 s \mathrm{stb} / \mathrm{d} y$ & 0.309 & 0.309 & 0.276 & 1659.79224 & 1.5 & 2.48968336 \\
\hline & & 7.005 & 7.005 & 0.448 & 2694.15552 & 1.81 & 4.876421491 \\
\hline & & & & & & & 8.494768574 \\
\hline & & 0.442851 & 0.442851 & & & & \\
\hline & & Total Chem & & & & & \\
\hline & & 6013.74 & 6013.74 & $10 \times 316$ & & & \\
\hline & & & & & & & \\
\hline & & NPV & 31.8250 & & & & \\
\hline & & & & & & & \\
\hline & & Price of oll & 40 & \$/bal & & & \\
\hline & & Inflation rate & 3 & \$ & & & \\
\hline & & Discount rate & 10 & $\mathbf{s}$ & & & \\
\hline
\end{tabular}

\section{B. Economic Model}

\begin{tabular}{|c|c|c|c|c|c|c|c|c|c|c|c|c|}
\hline \multirow{3}{*}{$\begin{array}{l}\text { Time } \\
\text { Daws }\end{array}$} & \multirow{3}{*}{$\begin{array}{l}\text { Time } \\
\text { Years }\end{array}$} & \multirow{3}{*}{$\begin{array}{l}\text { Oil Production } \\
\text { stb/day }\end{array}$} & \multirow{3}{*}{$\begin{array}{l}\text { Oif Price } \\
\text { (5/bel) } \\
\text { mod }\end{array}$} & \multirow{2}{*}{$\begin{array}{l}\text { Alkali } \\
\text { MS }\end{array}$} & \multirow{3}{*}{$\begin{array}{l}\text { Surtertant } \\
\text { MS }\end{array}$} & \multirow{2}{*}{$\begin{array}{l}\text { Polverter } \\
\text { MS }\end{array}$} & Revesue & Opex & \multirow{2}{*}{\multicolumn{2}{|c|}{$\begin{array}{l}\text { Net conh flow } \\
\text { MS }\end{array}$}} & DCF & $\cos$ \\
\hline & & & & & & & & & & & & \\
\hline & & & & & & & $m \infty d$ & real terms & mod & real terms & & \\
\hline 0 & 0 & 0 & 40 & 0.0000000 & 0.0000000 & 0.0000000 & 0 & 0.0000000 & 0.0000000 & 10 & 0 & 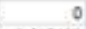 \\
\hline 30 & 0.082192 & 625.8983 & 40 & 0.0171009 & 0.0377226 & 0.0738852 & 0.75049967 & 0.1290217 & 0.6214780 & 0.6199699 & 0.615132 & 0.615132 \\
\hline 60 & $0: 64384$ & 6238969 & 40 & 0.0171009 & 0.0377226 & 0,0738852 & 0.75232522 & 0.1293355 & 0.6229857 & $0.61596 n$ & 0.610332 & 1.225465 \\
\hline 90 & 0.245575 & 623.8988 & 40 & 0.0171009 & 0.0377226 & 0.0738852 & 0.75415521 & 0.1296501 & 0.6225051 & 0.6199699 & 0.50557 & 1.831034 \\
\hline 120 & 0.325767 & 6235948 & 40 & 0.017000 & 0.037226 & $0.073 \% 652$ & 0.75598965 & 0.1296655 & 0.6260242 & 0.6159699 & 0.600644 & 2.431879 \\
\hline 150 & 0.410959 & 6238983 & 40 & 0.0171009 & 0.0377226 & 0.0738852 & 0.75782855 & 0.1302816 & 0.6275459 & 0.6199699 & 0596156 & 3.028035 \\
\hline 200 & 0.493151 & 6238968 & 41 & 0.0171009 & 0.0577226 & 00738352 & 0.75967193 & 0.1305985 & 0.6290734 & 0.6199699 & 0.591500 & 3.619539 \\
\hline 210 & 0.575342 & 623.9989 & $4 !$ & 0.0171009 & 0.0377226 & 0.0738852 & 0.76151979 & 0.1309162 & 0.8306036 & 0.6199699 & 0.586839 & 4.206428 \\
\hline 200 & 0.657594 & 623.8988 & 41 & 0.0171009 & 0.0377226 & 0.0738852 & 0.76337214 & 0.1312307 & 0.6321375 & 0.6199699 & 0.582309 & 4.788737 \\
\hline 270 & 0.732726 & 6238948 & 41 & 0.017009 & 0.0377226 & 0.0738852 & 0.765229 & 0.1315539 & 0.6336751 & 0.619969 & $0.57 m 65$ & 5.366502 \\
\hline 300 & 0.821918 & 6238983 & 41 & 0.0171009 & 0.0377226 & 0.0738552 & 0.76709038 & 0.1318739 & 0.6352165 & 0.6199699 & 0.573257 & 5.939759 \\
\hline 390 & 0.90411 & 6239988 & 41 & 0.0171009 & 0.0377236 & 0.0738832 & 0.76695828 & 0.1321946 & 0.6967616 & 0.6199699 & Q.568784 & 6.508542 \\
\hline 360 & 0.986301 & 6238988 & 41 & 0.0171009 & 0.0377226 & 0.0738852 & 0.77082673 & 0.1325162 & 0.8383105 & 0.6199699 & 0.564345 & 7.072888 \\
\hline 390 & 1060593 & 6238988 & 41 & 0.0171009 & 0.057226 & 0.0738532 & 0.7270172 & 0.1328385 & 0.6098632 & 0.6199699 & OS599032 & 7.632829 \\
\hline 420 & 1.150685 & 6239988 & 41 & 0.0171009 & 0.0377226 & 0.0738852 & 0.77458127 & 0.1331617 & 0.6414196 & 0.6199699 & 0.555572 & 8. 188402 \\
\hline 450 & 1232877 & 6238983 & 41 & 0.0171009 & 0.0577226 & 0.0738852 & Q.7nGessa & 0.1354856 & 0.5429798 & 0.6199699 & 0.551237 & 8.739639 \\
\hline 480 & 1315068 & 623.9259 & 42 & 0.0171059 & 0.0377226 & 0.0738652 & o.7n835411 & 0.1336103 & 0.6445638 & $0.61926 n$ & 0.546736 & 9.286575 \\
\hline$\$ 10$ & 1.39726 & 623.8989 & 42 & 0.0171009 & 0.0377226 & 0.0738852 & 0.78024741 & 0.1341358 & 0.6461117 & 0.6199699 & 0.542668 & 9.829243 \\
\hline 500 & 1.479452 & 623.8958 & 42 & 0.0171000 & 0.037226 & 0.0738452 & 0.78214592 & 0.1346620 & 0.6476833 & 0.6199699 & 0.588634 & 10.36768 \\
\hline 570 & 1561644 & 623.8983 & 42 & 0.0171009 & 0.0377226 & 0.0738852 & 0.78404785 & 0.1347891 & 0.6492587 & 0.6199699 & 0.534232 & 10.90191 \\
\hline$\infty 00$ & 1603856 & 6238968 & 42 & 0.0171009 & $0.05 m 226$ & $0.0758 s 52$ & 2.76s9ss & 0.1351170 & OAsossso & 0.6199699 & 0.530065 & 11.45197 \\
\hline 630 & 1726027 & 623.8983 & 42 & 0.0171099 & 0.0377226 & 0.0738852 & 0.78786679 & 0.1354456 & 0.6524212 & 0.6199699 & 0.525927 & 11.9579 \\
\hline 660 & 1808219 & 623.8988 & 42 & 0.0171009 & 0.0377226 & 0.0738352 & 0.78978323 & 0.1357751 & 0.6540081 & 0.6199699 & 0.521823 & 12.47972 \\
\hline 690 & 1890411 & 623.9968 & 42 & 0.0171009 & 0.0377226 & 0.0738852 & 0.79170434 & 0.1361054 & 0.655590 & 0.617069 & 0.517752 & 1299747 \\
\hline 720 & 1972603 & $623 \mathrm{A988}$ & 42 & 0.0171009 & 0.0377226 & 0.0738852 & 0.79363011 & 0.1364364 & 0.6571937 & 0.6199699 & 0.513712 & 1351119 \\
\hline 750 & 2054785 & 6238968 & 49 & 0.0171009 & 0.037226 & 0.0738852 & 0.79556057 & 0.1967683 & 0.6567923 & 0.6199699 & Q.50970s & 1402089 \\
\hline 700 & 2136966 & 6235948 & 43 & 0.0171009 & 0.0377226 & 0.9738852 & 0.79749573 & 0.1371010 & 0.6605947 & 0.6196699 & 0.505726 & 1452661 \\
\hline 810 & 2219178 & 623.8988 & 43 & 0.0171009 & 0.0377228 & 0.0733852 & 0.79943559 & 0.1374345 & 0.6620011 & 0.6199699 & 0.501779 & 15.02839 \\
\hline 300 & 230197 & 6238983 & 43 & 0.0171009 & 0.0377228 & 0.0758852 & 0.80138018 & 0.137ness & 0.6836114 & 0.6199699 & 0.497864 & 1552626 \\
\hline 870 & 2.383562 & 623.8983 & 43 & 0.0171009 & 0.0377226 & 0.0738852 & 0.80332949 & 01331039 & 0.6652256 & 0.5196699 & 0.493979 & 16.02024 \\
\hline 900 & 2465753 & 623.8983 & 43 & 0.0171009 & 0.0377226 & 0.0738852 & 0.80528354 & 0.1394398 & 0.6668437 & 0.6199699 & 0.490126 & 16.51036 \\
\hline 930 & 2547945 & 6238958 & 43 & 0.0171009 & 0.037226 & 0.0738552 & 0.00724235 & 0.1387766 & 0.66sesst & 0.6199699 & 0.4863 & 1699666 \\
\hline 960 & 2630137 & 623.8988 & 43 & 0.0171009 & 0.0377226 & 0.0733852 & 0.80920592 & 01391141 & 0.6700918 & 0.6199699 & 0.482505 & 17.47917 \\
\hline 990 & 2712329 & 6238988 & 43 & 0.0171009 & 0.097228 & 0.0756852 & 0.81117427 & 0.1594525 & 0.671217 & 0.6199699 & 0.47874 & 17.95791 \\
\hline 1020 & 2.794521 & 623.8983 & 43 & 0.0171009 & 0.0377226 & 0.0739852 & 0.81314741 & 01397917 & 0.6733557 & 0.6199693 & 0.475005 & 1843291 \\
\hline 1050 & 2876712 & 623.8988 & a4 & 0.0171009 & 0.0377226 & 0.0738852 & 0.81512534 & 01401318 & 0.6749936 & 0.6199699 & 0.471298 & 18.90421 \\
\hline 2060 & 2958904 & 6234968 & 4 & 0.0171009 & 0.0377226 & 0.0738552 & 0.81720809 & 01400726 & 0.5766355 & 0.619969 & 0.467621 & 19.37183 \\
\hline 1110 & 3041096 & 623.8989 & 44 & 0.0171009 & 0.0377226 & 0.0738852 & 0.81909566 & 01408143 & 0.6782813 & 0.6199699 & 0.463972 & 19.8358 \\
\hline 1100 & 8.123268 & 623.8988 & 4 & 0.0171009 & $0.03 m 228$ & 0.0788852 & 0.82108606 & 0.1411369 & 0.6799812 & 0.6199699 & 0.460351 & 2029615 \\
\hline 1170 & 3.205479 & 623.8983 & 4 & 0.0171009 & 0.0377226 & 0.0733852 & 0.82308531 & 0.1415002 & 0.6815951 & 0.619969 & 0.456759 & 20.75291 \\
\hline 1200 & 3.287671 & 623.8988 & 44 & 0.0171009 & 0.0377226 & 0.0738852 & 0.82508742 & 0.1618444 & 0.6832450 & 0.6199699 & 0.453195 & 21.20611 \\
\hline 1230 & 3364963 & 6238989 & 4 & 0.01731009 & 0.0377226 & 0.0738852 & 0.8270944 & 0.1421624 & 0.6949050 & 0.619669 & 0.429659 & $21.655 \mathrm{~m}$ \\
\hline 1260 & 3.452055 & 623.8983 & 44 & 0.0171009 & 0.0377226 & 0.0736852 & 0.82910626 & 01425953 & 0.6865710 & 0.6199699 & 0.44615 & 2210192 \\
\hline 1290 & 3534247 & 623.9988 & 4 & 0171009 & $0.037 m 226$ & 0.0786852 & $0.83112 \$ 02$ & 0.1428620 & 0.6452410 & 0.6199699 & 0.442669 & 22.54459 \\
\hline 1320 & 3.616438 & 623.8983 & 45 & 0.0171009 & 0.0377226 & 0.0733852 & 0.83314458 & 0.1432296 & 0.6899151 & 0.6199699 & 0.439214 & 22.9839 \\
\hline 1350 & 3.69363 & 623.8968 & is & 0.0171009 & 0.0377226 & 0.0738352 & 0.83517126 & 0.1435780 & 0.0915933 & 0.6199699 & 0.455787 & 23.41959 \\
\hline 1380 & 3.786822 & 623.8989 & 45 & 0.0173000 & 0.0377236 & 0.0738352 & 0.83720276 & 0.1439272 & 0.6932756 & 0.6196699 & 0.432387 & 23.85197 \\
\hline 1410 & 3863014 & 623.8988 & 45 & 0.0171009 & 0.0377226 & 0.0738652 & 0.83923921 & 0.1442773 & 0.6949619 & 0.6199699 & 0.425013 & 24.28099 \\
\hline 1440 & 3955205 & 6238968 & 45 & 0.0171009 & $0.037 \mathrm{~m} 228$ & 0.0738852 & 0.84128062 & 0.1446282 & 0.6966524 & 0.6196699 & 0.425665 & 24.30665 \\
\hline 1470 & 4027397 & 623.8983 & 45 & 0.0171009 & 0.0377226 & 0.0738852 & 0.84332698 & 0.1449800 & 0.6983469 & 0.6199699 & 0.422344 & 25129 \\
\hline 1500 & 4.109589 & 623.8983 & 45 & 0.0171009 & 0.0577226 & 0.0738852 & O.845378s3 & 0.3053527 & 0.7000456 & 0.6199699 & 0.419048 & 25.54804 \\
\hline 1530 & 4191781 & 6238989 & 45 & 0.0173009 & 0.0377226 & 0.0738852 & 0.84743467 & 0.1456862 & 0.7017485 & 0.6199698 & 0.415778 & 25.96382 \\
\hline 1560 & 4273973 & 623.8988 & 45 & 0.0171009 & 0.0377226 & 0.0738852 & 0.849496 & 0.1460406 & 0.7036554 & 0.6199699 & 0.412534 & 26.37635 \\
\hline 1596 & 4356164 & 623.5868 & 45 & 0.0173006 & $0.03 \mathrm{~m}_{226}$ & 0.0738852 & 0.85156235 & 0.1659958 & 0.3051665 & 0.6199695 & 0.408315 & 26.74567 \\
\hline 1620 & 4.438356 & 6238988 & 46 & & 0.0377226 & & 0.85353373 & & & & 0.406121 & \\
\hline $1650^{\circ}$ & 4520543 & 38988 & 45 & 1171009 & 0.0377226 & 7738852 & 0.85571015 & 0.1671089 & 0,7086013 & 0.6199699 & 0.402952 & 2759474 \\
\hline 2680 & 4.60234 & $623 \$ 569$ & 46 & 0.0171069 & 0.0377226 & 0.0738852 & 0.85779162 & 0.1676667 & 0.7103299 & 0.6196699 & 0.399807 & 27.9oess \\
\hline 1710 & 4684932 & 623.8983 & 46 & 0.0171009 & 0.0377226 & 0.0738852 & 0.85987815 & 0.1478254 & 0.7120527 & 0.6199699 & 0.396683 & 28.39124 \\
\hline 1700 & 476723 & 6238988 & 46 & 0.0173009 & 0.0377226 & 0.0758852 & 2.066196975 & $0.1<81450$ & Q.7337ses & 0.6198699 & 0393592 & 28.72883 \\
\hline 1770 & 4829315 & 623.8983 & 46 & 0,0171009 & 0.0377226 & 0.0738852 & 0.56406644 & 0.1435455 & 0.7155210 & 0.6199699 & 0.390521 & 29.17535 \\
\hline 1800 & $\angle 931507$ & 623.8988 & 46 & 0.0171009 & 0.0377228 & 0.0758852 & 20.86616824 & 0.1489068 & 0.7172615 & 0.6199699 & 0.387474 & 29.56282 \\
\hline 1830 & 501369 & 623.8983 & 46 & 0.0171009 & 0.0377226 & 0.0738852 & 0.86827514 & 02492690 & 0.7190062 & 0.6190699 & 0.38445 & 29.94727 \\
\hline 1860 & 5.09589 & 623.8988 & 47 & 0.0171009 & 0.0377226 & 0.0758852 & 0.87039718 & 01496321 & 0.7207551 & 0.6199699 & 0.38145 & 30.32872 \\
\hline 2890 & 5.178082 & $623 \approx 969$ & 47 & 0,0173009 & $0.03 m 226$ & 0.0738852 & $0.87250 \div 34$ & 0.149960 & 0.7225083 & 0.6196699 & 0.978474 & 30.7072 \\
\hline 1920 & 5.260274 & 623.8988 & 47 & 0.0171009 & 0.0377226 & 0.0738852 & 0.87462666 & 0.1503609 & 0.7242658 & 0.6199699 & 0.375521 & 3108272 \\
\hline 2950 & 5362466 & 6238988 & 47 & 0.0171069 & 0.0977226 & 0.0758852 & 0.87675416 & 0.1507267 & 0.7260275 & 0.6196699 & 0.37259 & 31.65531 \\
\hline 1980 & 5.424658 & 623.8985 & 47 & 0.0171009 & 0.0377226 & 0.0738852 & 0.8788868 & 0.1510933 & 0.7277935 & 0.6199699 & 0.369683 & \\
\hline
\end{tabular}

\section{ACKNOWLEDGMENT}

We want to acknowledge Mr. Out Tackie and All Nations University College for their contribution to the success of this paper and also, Mr. Evans Annan for his advice and directives. 


\section{REFERENCES}

[1] Abadli, F., 2012. Simulation Study of Enhanced Oil Recovery by ASP (Alkaline Surfactant and Polymer) Flooding for Norne Field C-segment, s.l.: s.n.

[2] Abido, M., 2009. Multiobjective particle swarm optimization for environmental /economic dispatch production. Electric Power Systems Reserach, Volume 79, pp. 1105-1113.

[3] Alvarez-Benitez, J. E., Everson, R. M. \& E., F. J., 2005. A MOPSO Algorithm Based Exclusively on Pareto Dominance Concept. In: C. A. Coello Coello, A. H. Aguirre \& E. Zitzler, eds. Evolutionary MultiCriterion Optimization. Guanajuato: Springer Berlin Heidelberg, pp. 459-473.

[4] Anon., n.d. Zargon Oil and Gas Limited. [Online] Available at: http://zargon.ca/operations/oilexploitation/tertiary-recovery/ [Accessed 2809 2018].

[5] Bandyopadhyay, S. \& Saha, S., 2013. Some Single- and Multiobjective Optimization Techniques. In: Unsupervised Classification. s.1.:Springer Berlin Heidelberg, pp. 17-58.

[6] Barnes, J. et al., 2010. Application of Internal Olefin Sulfonates and Other Surfactants to EOR. Part 1: Structure - Performance Relationships for Selection at Different Reservoir Conditions. Tulsa, Society of Petroleum Engineers.

[7] Bashir, H., 2016. Deloitte. [Online] Available at: http://www2.deloitte.com/uk/en/pages/energy-andresources/articles/crude awakening.html\# [Accessed 28 September 2018].

[8] Bataweel, M. \& Nasr-El-Din, H., 2011. Alternatives to Minimize Scale Precipitation in Carbonate Cores Caused by Alkalis in ASP Flooding in High Salinity/High Temperature Applications. Noordwijk, Society of Petroleum Engineers.

[9] Carrero, E., Queipo, N. V., Pintos, S. \& Zerpa, L. E., 2007. Global sensitivity of Alkaline-SurfactantPolymer enhanced oil recovery processes. Journal of Petroleum Science and Engineering, Issue 58, pp. 30-42.

[10] Cheng, J.-C.et al., 2001. Overview of Daqing ASP pilot. Petroleum Geology \& Oilfield Development in Daqing, 20(2), pp. 46-49.

[11] Clark, S., M.J, P. \& S.M, S., 1993. Design and Application of an Alkaline-Surfactant-Polymer Recovery System to the West Kiehl Field. Society of Petroleum Engineers, 1(01), pp. 172-179.

[12] Esquivel, S. C. \& Cagnina, L. C., 2008. Multi-Objective Optimization with Gaussian PSO algorithm. s.l., XIV Congreso Argentino de Ciencias de la Computacion.

[13] Gogarty, W. \& Tosch, W., 1968. Miscible-type water flooding: oil recovery with micellar solutions. J. Petrol. Technol, Issue 20, pp. 1407-1414.

[14] Gordon, K., 2015. Market Realist. [Online] Available at: http://marketrealist.com/2015/11/crude-oilprices-fall-geopolitical-tension-eases/ [Accessed 28 September 2018].

[15] Gubashov, R., 2015. ASP Optimization, Edinburgh: Heriot-Watt University.

[16] Hill, H., Reisberg, J. \& Stegemeir, G., 1973. Aqueous surfactant systems for oil recovery. J. Petrol. Technol, Issue 25, pp. 186-194.

[17] Hongfu, L. et al., 2003. Alkaline/Surfactant/Polymer (ASP) Commercial Flooding Test In Central Xing2 Area of Daqing Oilfield. Kuala Lumpur, Society of Pereoleum Engineering.

[18] Hou, J. et al., 2005. The role of viscoelasticity of alkali/surfactant/polymer solutions in enhanced oil recovery. Journal of Petroleum Science and Engineering, Issue 47, pp. 219-235.

[19] Kennedy, J. \& Russell, E., 1995. Particle Swarm Optimization. Piscataway, IEEE Service Center.

[20] Kokal, S. \& Al-Kaabi, A., 2010. Enhanced Oil Recovery: Challenges and Opportunities. World Petroleum Council: Official Publication, pp. 64-69.

[21] Muggeridge, A. et al., 2014. Recovery rate, enhanced oil recovery and technology limits. Philosophical Transactions of the Royal Society A.

[22] Ngatchou, P., Zarei, A. \& El-Sharkawi, A., 2005. Pareto multi objective optimization. In Proceeedings of the 13th International Conference on Intelligent System Application to Power Systems. s.l., IEEE.

[23] Office of Fossil Energy (US Department of Energy), undated. Energy.gov. [Online] Available at: http://energy.gov/fe/science-innovation/oil-gas-research/enhanced-oil-recovery [Accessed 28 September 2018].

[24] Olaijire, A. A., 2014. Review of ASP EOR (alkaline surfactant polymer enhanced oil recovery) technology in the petroleum industry: Propect and challenges. Energy, Issue 77, pp. 963-982.

[25] Olsen, D. et al., 1990. Design of a novel flooding system for an oil-wet Central Texas carbonate reservoir. Tulsa, Society of Petroleum Engineers.

[26] Patil, D. D. \& Dangewar, B. D., 2014. Multi-Objective Particle Swarm Optimization (MOPSO) based on Pareto Dominance Appraoch. International Journal of Computer Application, 107(4), pp. 13-15. 
Multi-Objective Function Approach of Optimizing Alkaline-Surfactant Polymer Flooding Performance using Particle Swamp Algorithm

[27] Praveen, J. \& Srinivasa Rao, B., 2014. Single Objective Optimization using PSO with Interline Power Flow Controller. International Electrical Engineering Journal, 5(12), pp. 1659-1664.

[28] Reyes-Sierra, M. \& Coello Coello, C. A., 2006. Multi-Objective Particle Swarm Optimizers: A Survey of the State-of-the-Art. International Journal of Computational Intelligence Research, 2(3), pp. 287-308.

[29] Ru-Sen, F. et al., 2013. Alkali/Surfactant/Polymer Flooding in the Daqing Oilfiled Class II Reservoir Using Associating Polymer. Journal of Chemistry.

[30] Savic, D., 2002. Single-objective vs. Multiobjective Optimization for Integrated Decision Support. Integrated Assessment and Decision Support, Volume 1, pp. 7-12.

[31] Sedaghat, M. H., Ahadi, A., Kordnejad, M. \& Borajani, Z., 2013. Aspect of Alkaline Flooding: Oil Recovery Improvement and Displacement Mechanisms. Middle East Journal of Scientific Research, Issue 18 , pp. 258-263.

[32] Sheng, J. J., 2013. A comprehensive review of Alkaline-Surfactant-Polymer (ASP) flooding. Monterey, Society of Petrolem Engineering.

[33] Shutang, G. \& Qiang, G., 2010. Recent progress and evaluation of ASP flooding for EOR in Daqing oil field. Muscat, Society of Petroleum Engineers.

[34] Sorbie, K., 1991. Polymer-Improved oil recovery. Glasgow and London, Blackie and Son Ltd.

[35] Stegemeier, G., 1997. Mechanisms of entrapment and mobilization of oil in porous media, Improved Oil Recovery by Surfactant and Polymer. New York : Academic Press.

[36] Sydansk, R. D. \& Romero-Zeron, L., 2011. Reservoir conformance improvement, Richardson, TX: Society of Petroleum Engineers.

[37] Umar, A. \& Saaid, I., 2013. Silicate Scales Formation During ASP Flooding: A Review. Research Journal of Applied Sciences, Engineering and Technology, 6(9), pp. 1543-1555.

[38] Wang, H., G.Z., L. \& Song, J., 2006. Combined chemical flooding technologies. Technological Developments in Enhanced Oil Recovery, pp. 126-188.

[39] Weatherill, A., 2009. Surface development aspects of alkali-surfactant-polymer (ASP) flooding. Doha, Qatar, Internation Petroleum Technology Conference.

[40] Youyi, Z. et al., 2013. Current development and application of chemical combination flooding technique. PETROL. EXPLOR. DEVELOP, 40(1), pp. 96-103.

[41] Zerpa, L. E., Queipo, N. V., Pintos, S. \& Salager, J.-L., 2005. An optimization methodology of alkalinesurfactant-polymer flooding process using field scale numerical simulation and multiple surrogates. Journal of Petroleum Science and Engineering, Issue 47, pp. 197-208.

[42] Zhang, H., Dong, M. \& Zhao, S., 2010. Which one is more important in chemical flooding for enhanced court heavy oil recovery, lowering interfacial tension or reducing water mobility?. Energy Fuels, Issue 24, pp. 1829-1836.

[43] Zhang, Y., Wang, S. \& Dong, Z., 2014. Classification of alzheimer disease based on structural magnetic resonance imaging by kernel support vector machine decision tree. Progress in Electromagnetics Research, Volume 44, pp. 171-184.

[44] Zhang, Y., Wang, S. \& Ji, G., 2015. A Comprehensive Survey on Particle Swarm Optimization Algorithm and its Applications. Mathematical Problems in Enginnering, Volume 2015.

[45] Zielinski, K. \& Laur, R., 2006. Constrained Single-Objective Optimization Using Particle Swarm Optimization. Vancouver, IEEE.

Citation: Ejeh Chukwugozie Jekwu, et.al, (2019). "Multi-Objective Function Approach of Optimizing Alkaline-Surfactant Polymer Flooding Performance using Particle Swamp Algorithm”, International Journal of Petroleum and Petrochemical Engineering (IJPPE), 5(2), pp.20-41, DOI: http://dx.doi.org/10.20431/24547980.0502003

Copyright: (C) 2019 Authors. This is an open-access article distributed under the terms of the Creative Commons Attribution License, which permits unrestricted use, distribution, and reproduction in any medium, provided the original author and source are credited 